\title{
El tribunal constitucional peruano como supremo intérprete de la constitución *
}

Ernesto Blume ForTinI

\section{Introducción}

El presente trabajo es una investigación sobre el fenómeno del control de la constitucionalidad en el Perú, con énfasis en el control concentrado y en el Tribunal Constitucional peruano: fenómeno que tuvo su máxima expresión en la Constitución de 1979, con la inauguración del Sistema de Control Concentrado de la constitucionalidad y la elevación a rango constitucional del Sistema de Control Disperso de la constitucionalidad, configurando el Sub-Modelo Dual o Paralelo actualmente imperante en el país, que la Carta de 1993 ha mantenido.

La investigación pretende demostrar la hipótesis que es inherente a la calidad de ente de control concentrado de constitucionalidad, de normas infraconstitucionales de primer rango, la de ser titular de la primacía de la interpretación constitucional y, por consiguiente, que el Tribunal Constitucional peruano es el intérprete supremo de la Constitución; calidad que, por lo demás, a pesar de la omisión en que incurre el texto de la Constitución de 1993 en este aspecto, le ha sido reconocida por los Artículos 39 y 40 , así como por la Primera Disposición General, de la Ley Orgánica del Tribunal Constitucional, Ley No. 26435. Para demostrarla se ha dividido el trabajo en tres capítulos.

El primero comprende el estudio del marco doctrinario que rodea la problemática de la constitucionalidad propiamente dicha, que constituye la materia de control, y los diversos sistemas de control de constitucionalidad que admite actualmente el Derecho Constitucional.

* Ensayo elaborado a raiz de los estudios realizados por el autor en la Maestría en Derecho con mención en Derecho Constitucional de la Escuela de Graduado de la Pontificia Universidad Católica del Perú. 
El segundo abarca la temática del control de constitucionalidad en el Perú, para cuyo efecto se ha realizado un rastreo del período comprendido entre la fundación de la República y la Constitución de 1979, para determinar así qué atisbos o normas existieron al respecto; se ha revisado el control de constitucionalidad a partir de la citada Constitución, con atención especial en el control concentrado de constitucionalidad; y se ha estudiado y reflexionado sobre el modelo de control de constitucionalidad actualmente vigente, justificando la tipificación particular del mismo que se asume.

El tercero se centra en el Tribunal Constitucional peruano y en la tarea que le corresponde como supremo intérprete de la Constitución, analizando la consustancialidad de la interpretación constitucional en el análisis de constitucionalidad, como elemento inherente al control concentrado de constitucionalidad; la técnica de interpretación constitucional; las características de la interpretación constitucional; y parte de la normatividad vigente, para establecer los retos y riesgos que se presentan a este ente de control concentrado de constitucionalidad, como máximo intérprete de la Constitución.

Para la realización del presente trabajo se utilizaron libros de doctrina sobre la materia y se revisaron los textos, actas y documentos originales, que en su mayoría constituyen textos de fuente directa.

\section{CAPÍTULO I}

\section{Marco Doctrinario}

Conforme se ha adelantado en la introducción del presente trabajo, en este capítulo, antes de abordar propiamente el caso peruano y el rol del Tribunal Constitucional en cuanto a la interpretación constitucional, se tratará sobre el marco doctrinario que rodea la problemática de la constitucionalidad, para cuyo efecto, en primer término, se intentará despejar la incógnita de ¿qué es la constitucionalidad? y, a partir de ese punto, ingresar propiamente a los sistemas de control de constitucionalidad reconocidos por la doctrina.

\section{La constitucionalidad}

Cualquier intento de escudriñar la problemática de la constitucionalidad, para lograr un acercamiento a su naturaleza y alcances, obliga a referirse 
al nacimiento y origen del constitucionalismo, el cual está íntima e indisolublemente ligado al fenómeno del poder político. Por consiguiente, subyace en tal intento la necesidad de despejar la incógnita que encierra el poder en general y el poder político en particular.

Al respecto, Karl Loewenstein, al tratar sobre lo que denomina la enigmática tríada, sostiene que "Los tres incentivos fundamentales que dominan la vida del hombre en la sociedad y rigen la totalidad de las relaciones humanas, son: el amor, la fe y el poder;..." ', los cuales son fuerzas vitales y consustanciales al ser humano, que vienen con él y forman parte de él; frente a las que el conocimiento se limita a la constatación de sus manifestaciones, pero no alcanza a la comprensión de su esencia. "Cualquier definición ontológica está abocada al fracaso, ya que la capacidad de percepción humana está confinada al resultado externo.» ${ }^{2}$, sentencia el mismo Loewenstein.

La contundencia de este último aserto podría resentir a cualquier investigador serio si la expresión no viniera de uno de los mas connotados constitucionalistas del presente siglo que, como bien se sabe, a través de sus reflexiones en torno al proceso del poder político, introdujo la hoy indiscutida multidimensionalidad del poder político, acabando con la tesis de la separación de poderes.

Sin embargo, se trata de un aserto cierto, nacido de la evidencia que siendo el poder inherente a la naturaleza humana, pertenece al misterio de la vida misma y, por lo tanto, como aquella, no tiene una explicación lógica, racional, convincente y absolutamente satisfactoria para el entendimiento de los seres humanos; los cuales deben limitarse a su constatación, a través de las manifestaciones que se producen de éste en lo fáctico. Más que entender las entrañas mismas del poder, se trata de constatar sus efectos y, a partir de allí, construir una racionalidad.

Ahora bien, estas tres fuerzas vitales, que son energías que nacen, se desarrollan y fenecen con el hombre y lo orientan hacia el logro de sus objetivos, forman parte de la naturaleza humana, por lo que están presentes en todas las personas; empero, en distinta proporción en cada una. Así, habrá algunas cuyo amor las lleve a grandes sacrificios, otras que estarán movidas por la fe, mientras que en muchas el poder será el impulso de sus acciones. Al respecto, es curioso observar que "La historia muestra cómo el amor y la fe han contribuido a la felicidad del hom-

1 Lotwhenstin, Karl. Temria de la constitución. Barcelona, Editorial Ariel, 1982. p. 24. 
bre, y cómo el poder a su miseria." ${ }^{3}$, lo cual revela que las dos primeras (el amor y la fe) pareciera que están ligadas a la virtud y la tercera (el poder) a la sensualidad, al exceso, al abuso y, en general, a la negatividad.

Cuando los efectos del poder comprometen a una colectividad y están en función de su organización éste es político. Por consiguiente, el poder político se da en la dimensión de la estructura y el funcionamiento de la sociedad, permitiendo "...incorporar un orden donde la autoridad debe conseguir una convivencia social acorde con el derecho." ${ }^{4}$; constituye la infraestructura dinámica de la institucionalización sociopolítica.

Dicho poder político debe ser regulado en su ejercicio, para que sus detentadores no incurran en los excesos ni abusos que pueden darse por el propio carácter de esta energía vital, que, como está dicho, viene lamentablemente ligada a la negatividad; dándose por tanto en paralelo al fenómeno del poder político, la necesidad de regular su ejercicio.

Es frente a esta necesidad de regulación del ejercicio del poder político que se origina el constitucionalismo, para que la organización de los estados y, en general, la vida social, se de en un marco de respeto a los derechos de sus miembros, en aras de lograr el bienestar general, con justicia y en libertad; evitando los excesos y abusos en el ejercicio del poder político, a través de mecanismos de compensación e intercontrol. Por eso:

«La historia del constitucionalismo no es sino la búsqueda por el hombre político de las limitaciones al poder absoluto ejercido por los detentadores del poder, así como el esfuerzo de establecer una justificación espiritual, moral o ética de la autoridad, en lugar del sometimiento ciego a la facilidad de la autoridad existente. ${ }^{5}$.

En este orden, la Constitución debe entenderse como el instrumento normativo fundamental de plasmación objetiva de la regulación del ejercicio del poder político, que contenga las reglas básicas para el equilibrio entre gobernantes y gobernados, fijando límites y controles al poder de los primeros y derechos y obligaciones para los segundos, a los efectos de, siguiendo a Vanossi ${ }^{6}$, dar cumplimiento a su función

4 Silva Pan:z, Max. El fenómeno del poder politico y su enseñanza en la facultad de Derecho y Ciencias Politicas. Tesis presentada para obtener el título de abogado en la Facultad de Derecho y Ciencias Políticas de la Unversidad de Lima, 1995. p. 171.

s Lohwinsthin, Karl. Op. cit., p. 150.

- Vanossi, Jorge Reynaldo. El Estado de Derecho en el Constitucionalismo Social. Buenos Aires, Editorial Universitaria de Buenos Aires, 1982. 
distribuidora -tratamiento de las limitaciones a los gobernantes- y a su función regularizadora -tratamiento del equilibrio de las relaciones entre gobernantes y gobernados. Debe comprender, además, un proyecto político -conjunto de ideales y principios del pueblo-, una respuesta social -conjunto de normas de coyuntura que el Legislador Constituyente formula en atención a los requerimientos de la realidad sobre la que norma- y un contrato social -conjunto de acuerdos a los que arriban las distintas fuerzas políticas representadas en la respectiva asamblea constituyente.

Para que una Constitución cumpla realmente sus fines y no se convierta simplemente en un cúmulo de buenas intenciones del Legislador Constituyente, es imprescindible que sea complementada con el conjunto de leyes y demás disposiciones reglamentarias que aseguren su operatividad; las cuales deben guardar armonía y concordancia plena con sus postulados. Esto es, no desnaturalizarla, no desbordarla, no contradecirla ni entrar en pugna con ella. En otras palabras, serle compatibles, por el fondo y por la forma. No incurrir en inconstitucionalidad.

Es en este punto del análisis, que corresponde referirse al tema de la constitucionalidad, cuya importancia salta a la vista, si se tiene en cuenta que, en gran medida, el éxito de una Constitución depende del que sus normas reglamentarias mantengan su inspiración, su racionalidad, su lógica $y$, en general, su plena vigencia.

Ante la pregunta ¿qué es la constitucionalidad?, la doctrina no ha brindado una respuesta clara y precisa, a pesar que se refiere a esta figura del Derecho Constitucional en forma reiterada, lo cual obliga a asumir la responsabilidad de intentar una respuesta en los siguientes términos: la constitucionalidad es un vínculo de armonía y concordancia plena entre la Constitución y las demás normas que conforman el sistema jurídico que aquella diseña; tanto en cuanto al fondo como a la forma. Es una suerte de cordón umbilical que conecta o une los postulados constitucionales con sus respectivos correlatos normativos, en sus diversos niveles de especificidad; siendo consustancial al proceso de implementación constitucional e imprescindible para la compatibilidad y coherencia del sistema jurídico.

La determinación de la existencia o inexistencia de ese vínculo entre la norma constitucional y la norma reglamentaria (ésto es, de constitucionalidad) está ligada al tema de la interpretación constitucional, desde que conociendo a cabalidad el espíritu, los alcances y el auténtico sentido de cada norma constitucional, se podrá establecer si la norma reglamentaria ha mantenido su espíritu, sus mismos alcances y su 
verdadero sentido; o si por el contrario, los ha desnaturalizado. Si es constitucional o no.

En tal sentido, constitucionalidad e interpretación constitucional son dos elementos inseparables, por lo que para determinar cuando se está ante la primera es necesario manejar una adecuada técnica de interpretación constitucional. Al respecto, en el Capítulo III del presente trabajo se ahondará en la consustancialidad de la.interpretación constitucional en el análisis de constitucionalidad.

\section{El control de constitucionalidad}

En este orden de ideas, frente a los numerosos casos de dispositivos legales que, aunque formalmente bien aprobados dentro de los propios órdenes constitucionales, desbordaban los alcances de las cartas constitucionales, llegando a incurrir en abierta y flagrante contradicción con sus principios y postulados, se fueron dando diversas reacciones, con el propósito de impedir que las normas inconstitucionales fueran aplicadas y se estuviera ante el insólito hecho que, aun dentro del propio Estado de Derecho y en el marco de vigencia de la Constitución, ésta fuera violada; reacciones que fueron formando la doctrina que ha dado base a la denominada Jurisdicción Constitucional, rama del Derecho Constitucional que estudia, entre otros importantes aspectos, los mecanismos de control de la constitucionalidad y, dentro de éstos, los siguientes modelos o sistemas:

\section{1. El Modelo Americano}

Casi en forma unánime los constitucionalistas aceptan que el primer antecedente sobre el control de constitucionalidad lo constituye el caso Marbury versus Madison, sobre el cual resulta ilustrativo hacer una breve reseña, precisando que el mismo se origina a principios del Siglo XIX, a raíz de la intervención de John Marshall, presidente de la Corte Suprema de Justicia de los Estados Unidos, en una reclamación promovida por William Marbury -quien fuera afectado por la negativa de la administración del presidente Thomas Jefferson de reconocer la creación de 42 judicaturas de paz en la ciudad de Washington y las designaciones respectivas, que se habían producido en los últimos días de la administración de su predecesor, el presidente Adams -, contra James Madison, quien era el Secretario de Estado. 
El 24 de febrero de 1803, la Corte Suprema de los Estados Unidos emitió un fallo, que fuera diseñado por el propio juez John Marshall, en el que, entre otros puntos, estableció "... el principio de la primacia de la Constitución como texto normativo fundamental del Estado." ${ }^{7}$ y la inaplicabilidad, por incompatibilidad, de la disposición que desconocía la creación de las precitadas judicaturas y respectivas designaciones.

Este Modelo Americano, también denominado de Revisión Judicial (judicial review), de Control Disperso, de Control Difuso o de Control Judicialista "...operaba sólo a pedido de parte, en causa pendiente y con efectos de no aplicación, o sea, de alcance relativo. \".

Es interesante anotar, que en este sistema el control de constitucionalidad corresponde a los jueces y magistrados, quienes, al resolver los casos concretos que conocen, si observan que entre las posiciones jurídicas que tienen las partes existe incompatibilidad entre una norma constitucional y una de inferior jerarquía deben preferir la primera. Nótese que se trata de un control puntual, en el caso concreto, de inaplicación excepcional de la norma inconstitucional, que no tiene efecto general y que no anula ni deroga la norma. Nótese también que la facultad de control no corresponde a un ente especial, sino que está distribuida o repartida entre los jueces y magistrados del Poder Judicial, como una atribución adicional a las que poseen y corresponden a su función jurisdiccional.

Para concluir con la referencia a este modelo, debe enfatizarse que, como lo detalla Furnish, la propia Corte Suprema de los Estados Unidos ha establecido las siguientes limitaciones a la revisión judicial: a) La validez constitucional es la última cuestión que la Corte considerará con respecto a una ley; b) Se requicre un "caso o controversia» auténtico para probar la validez de una Ley del Congreso; c) La Corte Suprema no intervendrá en una "cuestión política"; y d) La Corte Suprema, a su propia discreción, puede decidir no considerar un caso".

7 Comisión Andina de Juristas. "Jurisprudencia, Caso Marbury ns. Madison". En Lecturas sobre Temas Constitucionales No. 2. Lima, Conisión Andina de Juristas, 1988. p. 100.

* Garcia Bhlauniok, Domingo. "La acción de inconstitucionalidad en el Derecho comparado». En Lecturas Constitucionales Andinas No. L. Lima, Comisión Andina de Juristas, 1991. p. 185.

" Furvish, Dale B. "La Revision Judicial" de la constitucionalidad de las leyes en los Estados Unidos". En el colectivo "Sobre la jurisdicción constitucional". Lima, Fondo Editorial de la Pontificia Universidad Católica del Perú, 1990. pp. 90-96. 


\subsection{El Modelo Europeo}

El Modelo Europeo, Modelo Austríaco, Modelo Kelseniano, Modelo de Control Ad-Hoc o Modelo de Control Concentrado de Constitucionalidad fue ideado por Hans Kelsen e inaugurado con la creación en 1919 del Tribunal Constitucional de Austria; siendo, al año siguiente, reconocido en la propia Constitución austríaca de 1920. Este modelo se caracteriza por confiar el control de la constitucionalidad a un ente especial, cuyas resoluciones hacen inaplicable la norma inconstitucional. Esto es deja de tener vigencia en lo sucesivo. Sobre este modelo García Belaunde afirma:

«Se caracteriza por confiar el control constitucional a un órgano jurisdiccional especial y concentrado, pero que está fuera de la triada clásica de poderes y sin relación de dependencia con el Poder Judicial, aparte de otras características. ${ }^{10}$.

De otro lado, el mismo García Belaunde agrega:

«Hoy este modelo se encuentra difundido en Europa y otros países, a diferencia del modelo llamado americano,.., tiene el carácter de concentrado, abstracto y derogatorio.» ${ }^{11}$.

En efecto, es concentrado porque un solo órgano es el que ejerce cl control de constitucionalidad (en muchos casos en forma exclusiva y excluyente respecto de los otros órganos del Estado), de manera que la facultad o el poder de control está, como su nombre lo indica, concentrada en el ente que detenta dicha facultad o poder; es abstracto porque analiza la norma cuestionada en forma aislada e independiente del caso concreto que pueda haber dado origen a su cuestionamiento (realizando una suerte de análisis de puro derecho entre la norma constitucional y la norma de menor jerarquía objeto de impugnación, para descubrir si contiene algún vicio de inconstitucionalidad); y es derogatorio, porque anula la ley o la norma cuestionada, la cual deja de tener vigencia y efectos para todos, por lo que la declaración de inconstitucionalidad seráa expresa y de alcance general (erga omnes).

11) Garcita Bhlaunde, Domingo. Op. cit., p. 185.

1 Garcia Bllaunde, Domingo. Esquema de la Constitución Peruana. Lima, Ediciones Justo Valenzuela E.I.R.L., 1992. p. 162. 
Antes de concluir con la referencia a este modelo de control de constitucionalidad, no debe obviarse a Sieyés, quien fue el precursor de este sistema, al proponer, en 1795, la creación de un jurie constitutionnaire $\mathrm{y}$, en un segundo proyecto, la creación de un organismo al que se le atribuiría la función de velar por la vigencia de la Constitución. Por tal razón, Francisco Fernández Segado acota con acierto:

«Al margen ya de esas funciones, en el proyecto de Sieyés existía un artículo clave: el VIII. A tenor del mismo: «Les actes declarés inconstitutionnles par arret du jury constitutionnaire, sont nuls et comme non avenues». La importancia de un precepto de esta naturaleza es verdaderamente notoria, pues es la primera vez que con claridad se establece como sanción de la declaración de inconstitucionalidad, la nulidad del acto inconstitucional.» ${ }^{12}$.

\subsection{El Modelo Político}

El Modelo Político de Control de Constitucionalidad tiene sus orígenes en las constituciones francesas de 1799 y 1852 , a partir de las cuales va cobrando importancia y reconocimiento en el decurso del siglo XIX, dándose posteriormente en diversos países. Sobre el mismo, García Belaunde sostiene:

«Se llama político, porque confia a un órgano político, en este caso el legislativo, el control de constitucionalidad. Como tal, ha funcionado sin grandes consecuencias, y además es quizás el menos orgánico. Cabe destacar que durante mucho tiempo -y aún ahora- muchos países contemplan entre las funciones del Parlamento, respetar y cuidar de la observancia de la Constitución..$^{13}$.

Se trata de un control previo a la aprobación de la norma, que se da paralelamente o al final, según los casos, del proceso de debate y aprobación del proyecto respectivo, al interior del propio Poder Legislativo,

12 Fernandeiz Sricamo, Francisco. "El Modelo Francés de Control Politico de la Constitucionalidad de las Leves: Su Evolución". En el colectivo Sobre la Jurisdicción Constitucional. Lima, Fondo Editorial de la Pontificia Universidad Católica del Pcrú, 1990. p. 111 .

1.3 García Brelaunde, Domingo. "La Acción de Inconstitucionalidad en el Derecho Comparadom. Op. cit., p. 186. 
que opera mediante una comisión ad hoc que tiene la función de detectar cualquier vicio de inconstitucionalidad que se da respecto de los proyectos que son materia de discusión, debate y aprobación. Es un control preventivo, que advierte y evita la inconstitucionalidad; el cual corresponde al propio órgano encargado de reglamentar la Constitución. Esto es al Poder Legislativo.

En Francia ha tenido gran auge por la vocación parlamentarista de ese país y por su arraigada tradición antijudicialista, fruto de, como bien lo señala Francisco Fernández Segado, razones históricas (confianza sin límites en la voluntad general y extremado recelo frente a los jueces), razones ideológicas (doctrina de Montesquieu sobre la separación de poderes y el carácter democrático - radical y asambleario proveniente del período revolucionario) y razones prácticas (asegurar una tutela contra la ilegalidad y los abusos del Poder Ejecutivo, mas que contra los excesos del Legislativo) $)^{14}$.

\subsection{Los otros modelos}

Además de los modelos a los cuales se ha hecho referencia líneas arriba, a los que, siguiendo al mismo García Belaunde, podría denominárseles modelos originarios, se dan otros modelos que derivan de los originarios y que constituyen bien una combinación de ellos o bien una aplicación conjunta de los mismos, que podrían ser catalogados en dos sub-modelos: el Sub-Modelo Mixto y el Sub-Modelo Dual o Paralelo.

El Sub-Modelo Mixto se da como resultado de la combinación, mezcla o fusión de dos o más modelos originarios, creándose uno nuevo, que viene a ser distinto de los originarios que le sirvieron de base, como es el caso del modelo aplicado en el Brasil, en el cual a pesar de la existencia de un control disperso de constitucionalidad se ha incorporado la acción directa de inconstitucionalidad, bajo las modalidades interventiva y genérica (la primera cauteladora del orden interno respecto de los ordenamientos federales y la segunda cauteladora de la constitucionalidad de las leyes en general).

El Sub-Modelo Dual o Paralelo se da como resultado de la aplicación de dos o más modelos originarios, que coexisten en forma independiente y autónoma, manteniendo cada uno de ellos sus propias características, como es el caso peruano, en el cual se tienen el Sistema de Con- 
trol Disperso y el Sistema de Control Concentrado de constitucionalidad y respecto del cual se tratará en la parte final del Capítulo II de la presente investigación.

\section{CAPÍTULO II}

\section{El control de constitucionalidad en el Perú}

\section{Consideraciones previas}

Como bien afirmaba don Manuel Vicente Villarán, en «...frase que se ha becho célebre $-y$ que luego otros han repetido sin citar la fuente...$-{ }^{\prime}$ "...el Perú ha vivido haciendo y deshaciendo constituciones. »; a tal punto que en sus casi ciento cincuenta años de vida republicana son doce las constituciones que ha tenido, sin contar una serie de «instrumentos normativos con pretensión constitucional» que, en diversas épocas, dictadores de turno y gobiernos de facto impusieron.

Esta cantidad de constituciones, cuya vigencia promedio no supera los quince años, es un reflejo de los problemas de origen que presenta el Perú, cuya formación, como la de los demás estados nacionales de América Latina fue distinta a la de los estados nacionales europeos.

En efecto, aquellos se formaron a través de un largo y lento proceso, que duró más de tres siglos, en el cual los acontecimientos fueron consecuencia de un desarrollo de la concepción del mundo y de una toma de conciencia de la necesidad de formarse como estados independientes, unida a elementos culturales, étnicos, tradicionales e históricos, entre otros, de cada pueblo, en el marco del avance de las ideas que, partiendo de una concepción absolutamente teológica del poder, fueron trasladando su titularidad, primero al monarca, sujeto a las leyes de Dios y de la naturaleza, y finalmente al pueblo, en una evolución que fue de la monarquía absoluta a la democracia plena, con ciertas modalidades intermedias, algunas de las cuales perduran hasta hoy en día, como es el caso de España e Inglaterra, por citar tan sólo dos ejemplos.

En cambio en América Latina, la formación de los estados nacionales

1 Garcia Bhlaundr, Domingo, con la colaboración de Gutiérrez Camacho, Walter. Las constituciones dol Perú. Lima, Edición Oficial, 1993. p. 9

Loc. cit. 
fue consecuencia de un corto período, comprendido entre 1780 , año en que se produjo la rebelión de José Gabriel Condorcanqui, considerada como el evento que marca el inicio de la emancipación americana, quien a nombre de los indígenas de las tierras conquistadas, se levantó contra los representantes de la corona española (en circunstancias en que el centro del poderío español se encontraba en el Perú), y el primer tercio del siglo XIX, en que ya se había producido la declaración de la independencia de los nuevos estados. Este corto período entre el inicio de la gesta emancipadora y la creación formal de los estados nacionales, no permitió el adecuado desarrollo de la conciencia necesaria para la constitución de los mismos.

De otro lado, los estados nacionales en América Latina surgieron dentro de un contexto sui géneris y atípico, caracterizado por la existencia de una serie de elementos y de fuerzas que provocaron, simultáneamente, energías centrífugas y centrípetas; por lo que puede afirmarse que la emancipación americana no correspondió en verdad a un movimiento unánime, coherente, deseado por todos los involucrados y conscientemente aceptado; sino que fue en cierta medida un fenómeno impuesto por las circunstancias, en cuya base se daba un tejido social enmarañado y complejo, así como impregnado de intereses, fuerzas y posiciones contradictorias. El Perú no sólo no fue ajeno a este contexto, sino que en él se dieron con más énfasis estas contradicciones; al punto que el célebre Jorge Basadre sostuviera :

«Por el mayor enraizamiento de la tradición colonial, por la abundancia de funcionarios, nobles y comerciantes prósperos dentro del régimen vigente, por las condiciones excepcionales que supo desplegar el virrey Abascal, el Perí no sólo resultó el país menos movido por la conmoción libertadora sino el paladín de la resistencia colonial. Fueron necesarias las intervenciones argentina, chilena y colombiana para libertar al Perú.»3 .

Es ciertamente un inicio débil, dubitativo y sin convicción popular, que permite entender la razón de su posterior decurso y de su situación actual.

Es de relevar, por tanto, que el Perú, insólitamente, nace como Estado nación en medio de una abierta contradicción entre dos elementos, cuyo ensamble y armonía resultaban consustanciales para su real existen-

Basabrt, Jorge, Perú: problema y pusibilidad. IV Edición. Lima, Consorcio Técnico de Editores, 1978. p. 19 
cia: la sociedad y el Estado formal. Por lo demás, aquella, desarticulada, ausente de una verdadera conciencia de nación, con grupos que tenían intereses distintos y hasta contrapuestos e, inclusive, con etnias en pugna; aquel, estructurado en base a modelos que no habían sido probados ni consultados al pueblo.

En este contexto se pretendió imponer un derecho importado, que no respondía a la realidad nacional, con textos que eran calco o remedo de los aprobados por los nacientes estados nacionales europeos, pero cuyo proceso de formación y creación había sido muy distinto al peruano; circunstancia a la cual se sumó en un curioso y peculiar fenómeno, el que los hechos políticos (en un marco en que el caudillismo, la improvisación, el oportunismo y la primacía de los intereses individuales y grupales sobre los nacionales eran el común denominador) fueran sometiendo al derecho, al punto de convertirse en su fuente principal.

Divorcio entre sociedad y Estado formal, importación de derecho cuando no derecho impuesto por los hechos políticos coyunturales, sumados a una crisis atípica, sui géneris, permanente y retroalimentada, han significado que el Pcrú aún sea un Estado nación en formación, como lo sostiene con acierto Enrique Bernales Ballesteros.

En este orden de ideas, las constituciones no han correspondido a las realidades que se pretendía regular. No han sido una efectiva respuesta a los aquí y ahora de cada momento histórico. Por ello, los detentadores del poder no han vacilado en dejarla de lado $y$, con la pasividad en algunos casos o anuencia del pueblo en otros, cambiarla.

No obstante ello, los Legisladores Constituyentes han hecho esfuerzos, tímidos al principio y mas intensos y valientes en las últimas constituciones, para rescatar, resguardar y defender dos valores que, sin lugar a dudas, son esenciales para la vigencia del sistema democrático, del estado de derecho y de la institucionalidad del país: la persona humana y la constitucionalidad.

Interesa esta última, porque siendo la constitucionalidad el vínculo de armonía y concordancia plena entre la norma constitucional y sus correlatos reglamentarios, en sus diversos niveles de especificidad, si ésta no se resguarda no existe garantía que, aun dentro de la vigencia de una Constitución, se esté en un verdadero Estado de Derecho, en el cual gobernantes y gobernados, sin distinciones de ninguna naturaleza, se sometan a la Constitución y a sus disposiciones reglamentarias.

Desde esta perspectiva, si se quiere garantizar en el Perú la vigencia de la Constitución, su supremacía, el fortalecimiento del sistema democrático, el mantenimiento y reforzamiento del Estado de Derecho y, en general, afincar la institucionalidad, el tema del control de la 
constitucionalidad resulta de vital importancia.

¿Existió desde los albores de la República una noción clara de la problemática de la constitucionalidad? ¿Concibieron los primeros legisladores que era necesario el establecimiento de mecanismos de control de constitucionalidad desde los inicios de nuestra vida democrática?, ¿Qué ocurrió en esta temática en el presente siglo y, concretamente en la vigente Carta de 1993?, son preguntas que exige una investigación rigurosa.

A partir del análisis del control de constitucionalidad, a través del desarrollo de nuestra vida republicana, es factible arribar a una tipificación del sistema actualmente vigente de control de constitucionalidad en el Perú, que comprenda la experiencia del Tribunal de Garantías Constitucionales creado por la Constitución de 1979 y desactivado a partir del golpe de Estado del 5 de abril de 1992, para arribar a un estudio concreto y puntual del Tribunal Constitucional creado por la Carta de 1993 y, ya en el siguiente capítulo, específicamente, respecto a la tarea que le compete como supremo interprete de la constitución.

\section{El control de constitucionalidad antes de la Constitución de 1979}

\subsection{Los primeros atisbos}

Pese a que los textos constitucionales anteriores a la Constitución de 1979, excepción hecha de las cartas de 1856 y 1933, presentan como común denominador en torno al control concentrado y al control difuso de la constitucionalidad un marcado silencio, ninguno de ellos fue totalmente ajeno a lo que Jorge Danós y Martha Sousa, siguiendo a Zárate Polo, describen como "...una cierta preocupación por el control de la constitucionalidad de las normas. $»^{4}$, pero orientada y basada en lo que el connotado constitucionalista español Francisco Fernández Segado ha denominado la mas pura línea Gaditana ${ }^{5}$, consagrada en la Constitución Política de la Monarquía Española, promulgada por el rey Fernando VII para España y sus colonias, conocida como Constitución de Cádiz de

\footnotetext{
4 Danós Ordoñtz, Jorge; Sousa Calle, Martha. "El control jurisdiccional de las nurmas jurídicas de carácter general". En La Constitución Peruana de 1979 y su problemas de aplicación. Lima, Cultural Cuzco S.A., 1987. p. 288

FERNÁNIDEZ SF(aA), Francisco. Seminario jurisdicción constitucional. Lima, versión magnetofónica de conferencia dictada el 13.06.96.
} 
1812, cuyos artículos Nos. 372 y 373, ubicados dentro del Capítulo Unico de su Título X denominado "De la observancia de la Constitución, $y$ modo de proceder para hacer variaciones a Ella., ${ }^{6}$, textualmente señalaban:

Artículo $372^{\circ}$.- Las Córtes en sus primeras sesiones tomarán en consideración las infracciones de la Constitución que se les hubieren hecho presentes, para poner el conveniente remedio, y hacer efectiva la responsabilidad de los que hubiesen contravenido á ella.?

Artículo 373. - Todo español tiene derecho de representar á las Cortes ó al Rey para reclamar la observancia de la Constitución. ${ }^{8}$.

Como se observa, se trataba en verdad de un atisbo de control de constitucionalidad, pero de orden eminentemente político, pues su ejercicio correspondía a la Corte y al Rey, y centrado mas que en una «infracción» normativa en una de carácter fáctico cometida contra los preceptos constitucionales, principalmente, por quienes ejercían cargo público, cuyo influjo se mantuvo en todas las Constituciones anteriores a la de 1979, sin excepción, dentro del entendimiento que era el Poder Legislativo el órgano al que correspondía el control de las infracciones a la Constitución.

En esta misma línea se encuentran, entre otros, los numerales 186 y 187 de la Constitución de 1823 (ubicados en su Capítulo IV -denominado "Observancia de la Constitución»- de su Sección Tercera); los artículos Nos. 47, inciso 4, y 150 de la Constitución de 1826 (ubicados en su Capítulo III -denominado "De la Cámara de Senadores»- de su Título V, y en su Capítulo Unico -denominado «De las Garantías»- de su Título XI, respectivamente); los preceptos Nos. 173 y 174 de la Constitución de 1828 (ubicados en su Título X denominado "Observancia de la Constitución y su revisión»); el numeral 178 de la Constitución de 1834 (ubicado en su Título XI denominado «Observancia y reforma de la Constitución»); el precepto No. 184 de la Constitución de 1839 (ubicados en su Título XIX denominado "Observancia de la Constitución»); el numeral 107, Inciso 1, de la Constitución de 1860 (ubica- 
do en su Título XIII denominado "Comisión Permanente del Cuerpo Legislativo»); y el precepto No. 83, Inciso 4, de la Constitución de 1920 (ubicado en su Título VIII denominado «Del Poder Legislativo»); debiendo hacerse hincapié que mas adelante se hará referencia específica a las constituciones de 1856 y de 1933, en razón que en ellas sí existen elementos mas destacables sobre la problemática del control de constitucionalidad.".

Al concluir esta breve referencia, debe enfatizarse que se trataba en verdad de un control respecto de los actos que constituían infracciones, violaciones o atentados contra la Constitución y no respecto de normas que, eventualmente, pudieran entrar en pugna con ella; y que, por lo demás, en forma unánime, en todos ellos se otorgaba al Congreso, entre otras, la atribución de interpretar las leyes, lo cual implicaba un análisis de legalidad, que, en el fondo, como siempre ocurre cuando se analiza la legalidad de una norma, conllevaba un análisis de constitucionalidad en forma implícita.

\subsection{La Constitución de $\mathbf{1 8 5 6}$}

Los legisladores constituyentes, que elaboraron las constituciones de $1823,1826,1828,1834,1839,1860,1867$ y 1920, no concibieron ni trataron, por cierto, el control concentrado de constitucionalidad ni el control difuso de constitucionalidad y, menos aún, imaginaron prever o establecer mecanismos procesales para su funcionamiento, ya que, como se ha adelantado, el andamiaje constitucional se asentaba en una concepción absolutamente dominada por la idea de que el Poder Legislativo era el primer poder del Estado y, como tal, las normas que el dictaba sólo podían ser interpretadas, revisadas y modificadas por el mismo, descartándose, por tanto, el examen explícito de constitucionalidad, en los términos que hoy recoge, acepta y propugna unánimemente el Derecho Constitucional.

Sin embargo, es curioso observar que la Constitución de 1856 terminó, aparentemente, con esta tradición, si se tiene en cuenta el texto de su artículo No. 10:

"Artículo 10.- Es nula y sin efecto cualquier ley en cuanto se oponga á la Constitución. Son nulos igualmente los actos de los 
que usurpen funciones públicas y los empleos conferidos sin los requisitos prescritos por la Constitución y las leyes.» ${ }^{10}$.

Sobre esta norma Jorge Danós y Martha Sousa coinciden en que fue la primera y, finalmente, la única de rango constitucional que antes de la Constitución de 1979 consagró, en forma expresa e inequívoca, «...el principio de que sería inválido todo acto legislativo dictado en contravención de las normas fundamentales.» ${ }^{11}$; y Aníbal Quiroga León agrega, que:

«Lo que si resulta novedoso, y pionero además, es que el embrión de un esbozo de Justicia Constitucional puede ser hallado en esta importante -pero de breve vigencia - constitución... ${ }^{12}$.

Si se trata de escudriñar en la motivación que tuvieron los miembros de la Convención Nacional encargada de elaborar la Constitución de 1856, para plasmar en su texto la norma contenida en el precitado artículo $10^{\circ}$, que se ha transcrito líneas arriba, salvo la propuesta del congresista Escudero, relacionada con la precisión de señalar «leyes secundarias ${ }^{\wedge}{ }^{3}$, presentada en la sesión de la Convención Nacional del sábado 5 de enero de 1856, no existen mayores luces que iluminen el análisis tendiente a descubrir las razones de la inclusión en el texto de la Constitución de 1856 del referido artículo 10, cuya primera parte fuera eliminada por el Constituyente de la Carta de 1860; eliminación respecto de la cual si aparecen algunos elementos de juicio, que constan en el Diario de Debates del Congreso reunido en 1860 para reformar la Constitución de 1856, por lo que por el camino residual quizás se pueden hallar algunos derroteros.

En dicho Diario de Debates, en la sesión del 11 de setiembre de 1860 , en la que se discutió sobre el texto sustitutorio del nombrado Artículo 10 que eliminaba su primera parte, aparece la intervención del Congresista Arenas ${ }^{14}$, miembro de la Comisión encargada de elaborar el proyecto, quien fundamentó las razones de tal eliminación.

10) Convención Nacional 1855 - 1856. Actas oficiales y extractos de las sesiones en que fue discutida la Constitución de 1860. Publicación ordenada por la Cámara de Diputados. Lima, Empresa Tipográfica La Unión, 1910. p. 595.

11 Danós Ordoñtz, Jorge; Sousa Callk, Martha. Op. cit., pp. 289-290.

12 AA.VV. Una aproximación a la justicia constitucional. Lima, Pontificia Universidad Católica del Perú. Fondo Editorial, 1990, p. 199.

13 Convención Nacional 1855 - 1856. Op. cit., p. 10.

14 Congreso de la República. Diario de Debates del Congreso reunido en 1860 que 
En la intervención del señor Arenas se encuentran algunos elementos importantes a considerar, reveladores de las ideas que en aquel entonces primaban en el criterio de los Legisladores Constituyentes, tales como:

- La conceptualización que las normas constitucionales tienen el carácter de sagradas e inviolables, por lo que las normas de inferior jerarquía que les sean opuestas carecen de legitimidad, en un reconocimiento expreso del principio de la jerarquía y primacía de la Constitución;

- La idea que animó a los constituyentes de la Carta de 1856 para aprobar el mencionado Artículo 10, cuando Arenas sostiene que "...quisieron sin lugar a dudas impedir los extravios de los Congresos, que realmente pueden dictar leyes opuestas a la Constitución ${ }^{15}$, revelando que existió la preocupación por establecer un freno al Poder Legislativo, una suerte de control de constitucionalidad, pero sin desarrollar cómo efectuarlo ni a través de quién; y

- La idea que sólo correspondía al Congreso frenar los excesos que pudieran producirse en su propio seno y, por consiguiente, que las leyes contrarias a la Constitución debían cumplirse, hasta que el Poder Legislativo las dejara sin efecto, como un mecanismo de impedir el caos que, según presumían, se produciría de mantenerse una norma como la del Artículo 10 de la Constitución de 1856.

\subsection{El debate producido el año 1923 en la Comisión Reformadora del Código Civil}

Después de los antecedentes que se han detallado, se produce un gran silencio normativo en la temática relacionada con el control de la constitucionalidad hasta 1923, año en el cual se lleva a cabo, en el seno de la Comisión Reformadora del Código Civil un interesante debate promovido por uno de sus miembros, el señor A. Solf y Muro, quien en la sesión No. 20, del 21 de febrero de 1923, propuso la inclusión en el Título Preliminar del proyecto el siguiente texto: "Cuando baya incompatibilidad entre una disposición constitucional y una legal, se preferirá la

ha reformado la Constitución dada por la Convención en 1856. Lima, Tipográfica del Comercio, 1860. p. 176.

15 Loc. cit. 
primera. $\gg^{16}$. Dicho texto fue debatido en la sesión No. 21 , del miércoles 28 de febrero de 1923, a la cual asistieron los señores Juan José Calle, M.A. Olaechea, Pedro M. Oliveira, A. Solf y Muro y Hermilio Valdizán, y actuaron como secretarios José M. Calle y Alberto Ulloa ${ }^{17}$; debate del cual pueden extraerse las siguientes conclusiones:

- Que el control disperso de constitucionalidad, creado a partir de su primer antecedente constituido por el caso Marbury versus Madison, plantaba sus primeras raíces en el Perú; y

- Que ya existía conciencia de la importancia y trascendencia del control disperso de constitucionalidad, aunque con cierta reserva, expresada a través de las reflexiones de los señores Solf y Olaechea, tanto es así, que éste último sostenía la tesis de reservar ese control solo a la Corte Suprema, por considerar excesivo que el mismo fuera ejercido por jueces inferiores; no obstante lo cual, a la postre, se impuso el criterio de señalar el principio y dejar para una reglamentación posterior la regulación específica del trámite de ejercicio del control en cuestión ${ }^{18}$.

Al final, quedó consagrada la fórmula que, trece años después, se recogiera en el artículo XXII del Código Civil de 1936, que a la letra ordenó:

"Cuando hay incompatibilidad entre una disposición constitucional y una legal se prefiere la primera". ${ }^{19}$.

\subsection{El anteproyecto de Constitución de la Comisión Villarán de 1931.}

La Junta de Gobierno que presidiera don David Samanez Ocampo designó, por resolución suprema del 7 de agosto de 1931, ampliada por las resoluciones supremas de 21 de agosto y 22 de setiembre del mismo año, una comisión presidida por el ilustre jurista don Manuel Vicente Villarán e integrada por los connotados hombres de derecho Víctor Andrés Belaunde, Diómedes Arias Schreiber, Carlos García Castañeda, Car-

\footnotetext{
in Comisión Reformadora del Código Civil Peruano (1923). Actas de las sesiones. Lima, Imprenta C.A. Castrillón, 1928. Tomo I, p. 102.

17 Ibid., pp. 102-103-104.

18 Comisión Reformadora del Código Civil Peruano (1923). Op. cit. p. 114.

$19 \quad$ Ibid., p. Tomo VIII, p. 40.
} 
los Doig y Lora, Jorge Basadre, José León Barandiarán, Toribio Alayza y Paz Soldán, Ricardo Palma, Luis Valcárcel, Emilio Romero y César Antonio Ugarte, a la cual encargó la elaboración de un anteproyecto de Constitución, que sería sometido al Congreso Constituyente convocado, precisamente, para fines del año 1931.

Esta comisión elaboró un magnífico anteproyecto, en el cual puso de relieve la inelubilidad de convertir a la Corte Suprema en el guardián de la constitucionalidad, recogiendo el sistema de control disperso. Lamentablemente, la Constituyente convocada con fecha 8 de diciembre de 1931 y a tres días de haberse producido la entrega del anteproyecto, lo desechó en un "...arranque de soberbia política y redactó por su cuenta su propio proyecto,... en el que introdujo muy poco de los articulos propuestos por la Comisión. .11 $^{21}$, según Luis Echecopar García.

En su exposición de motivos se dejaba sentado que, a pesar que las constituciones de 1860 y de 1920 no reprodujeron el Artículo 10 de la Constitución de 1856 , el principio que postula la nulidad de las leyes inconstitucionales o contrarias a la Constitución, estaba invívito en la teoría y la inspiración de los Legisladores Constituyentes de aquellas cartas, por cuanto en ambas se había normado que quienes ejercían función legislativa, no podían transgredir las limitaciones establecidas por la propia Constitución y que, por consiguiente, eran nulos aquellos actos perpetrados por quienes usurpaban las funciones públicas. Se agregaba en forma inédita que:

«La constitucionalidad como régimen político es la supremacía de la Constitución sobre la ley. La Constitución es ley para el legislador y no pude confiarse del todo en que el cuerpo legislativo, por estímulos morales y respeto a la opinión, guarde invariable respeto a las prohibiciones que la Constitución le impone. Teóricamente es de toda evidencia la invalidez de las leyes que infringen la Constitución». ${ }^{21}$.

Pero es más, no sólo se explicitó en aquella exposición de motivos el principio de supremacía de la Constitución y la constitucionalidad como consustancial a la validez de las normas jurídicas, sino que se invocó el principio de la no aplicación de las leyes inconstitucionales; reprobando

20 Echrcopar Garcia, Luis. "Prólogo". En Anteproyecto de Constitución de $1931 d e$ la Comisión Manuel Vicente Villarán. Lima, P.C. Villanueva, 1962. p. 19.

21 Comisión Manuel Vicente Villarán De 1931. Anteproyecto de Constitución de 1931. Lima, P.C. Villanueva, 1962. p. 77. 
la validez de las leyes infractoras de la Constitución, así como ingresando a la reflexión y al esbozo de lo que podría denominarse el diseño de la implementación del control disperso de constitucionalidad, sin dejar de lado las consideraciones y preocupaciones, así como recelos que planteaba la propuesta de establecer un sistema que buscaba romper con una tradición y que disentía de las tesis imperantes hasta aquel entonces ${ }^{22}$. En tal sentido, el aporte de la Comisión Villarán resulta trascendental en el desarrollo del control de constitucionalidad en el Perú.

El artículo 142 del anteproyecto de la Comisión Villarán consagraba el principio de la no aplicación de las leyes inconstitucionales; establecía la obligación de los jueces de respetarlo en los casos que juzgaban; señalaba que las sentencias que omitían aplicar la ley inconstitucional, se elevarían a la Corte Superior, vía apelación o, en ausencia de ésta, vía consulta; preceptuaba que las sentencias dictadas en segunda instancia con motivo de las apelaciones o consultas, según el caso, que declaraban que una ley se oponía a la Constitución, debían ser elevadas a la Corte Suprema, vía recurso de nulidad o, en ausencia de éste, vía consulta; establecía que las consultas debían ser sometidas a la Corte Suprema en pleno, como también aquellas cuestiones de inconstitucionalidad que se presentaban a nivel de la propia Corte Suprema en la Sala encargada de conocer los casos de competencia ordinaria; exigía para la declaración de "anticonstitucionalidad de una ley» el voto de las dos terceras partes del pleno de la Corte; precisaba que la declaración regía únicamente para el caso materia del litigio; y ordenaba a los jueces no aplicar los decretos y reglamentos (esto es, las normas de menor jerarquía que las leyes), que fueran contrarios a la propia Constitución o a las leyes. Nótese que en este último punto también se recogía una cautela al principio de legalidad y un correctivo a su violación, en el caso de normas infralegales ${ }^{23}$.

\subsection{La incorporación de la Acción Popular en la Constitu- ción de 1933}

Lamentablemente el proyecto de la Comisión Villarán fue desechado y, finalmente, la Constitución de 1933 vendría a utilizar los esquemas más clásicos del siglo XIX, considerando que era competente para conocer 
las infracciones a la Constitución el Congreso de la República y, en definitiva, convirtiéndolo en intérprete de la Constitución ${ }^{24}$. No obstante ello, la Carta de 1933 acogió en su artículo 133 el instituto de la acción popular, que parecía romper con esa pauta, pues preveía la atribución del Poder Judicial de un control de legalidad y, por lo tanto, de constitucionalidad de las normas infralegales (no de las leyes, sino de los decretos y normas reglamentarias); dejando a la ley el establecimiento del procedimiento judicial correspondiente. El artículo en referencia rezaba textualmente:

Artículo No. 133.- Hay acción popular ante el Poder Judicial contra los reglamentos y contra las resoluciones y decretos gubernativos de carácter general que infrinjan la Constitución o las leyes, sin perjuicio de la responsabilidad política de los Ministros.

La ley establecerá el procedimiento judicial correspondiente. ${ }^{25}$.

El Diario de Debates del Congreso Constituyente de 1931, consigna que en la sesión del martes 12 de abril de 1932, con motivo de la presentación del proyecto de Constitución, se leyó la fundamentación del precitado numeral, de la cual se desprende que la razón que llevó a los constituyentes a su consagración fue el haber comprobado que el Poder Ejecutivo, al ejercer su facultad de reglamentar las leyes había expedido "...multitud de disposiciones reglamentarias que infringen la Constitución o las leyes.» ${ }^{26}$, por lo que resultaba aconsejable y prudente poner limitaciones a tales excesos. En este sentido se señalaba textualmente:

"La Constitución, que es la ley matriz de la República, debe ser celosamente defendida. Ningún reglamento que infrinja la Constitución o la ley tiene fuerza coercitiva, y cualquiera del pueblo puede y debe denunciarlo ante el Poder Judicial, sin que esta acción popular impida o limite la acción del Parlamento para responsabilizar políticamente a los Ministros. $»^{27}$.

Acto seguido, reconociendo el carácter inédito de la incorporación de la acción popular en una carta constitucional peruana, y mos-

\footnotetext{
24 Frrnánimez Sticiado, Francisco. Loc. cit.

25 Ugarte Drl Pino, Juan Vicente. Op. cit. p. 589.

26 Congreso Constituyente De 1931. Diario de Debates. Lima, Editora La Nacional S.A., 1936. Tomo III, p. 2521.

27 Loc. cit.
} 
trando el criterio de la conveniencia de delegar a la ley la regulación procedimental respectiva, se agregaba:

«Disposición de tanta importancia que figurará por primera vez en nuestra Carta Política, reclama una ley que establezca el procedimiento judicial correspondiente. ${ }^{28}$

El texto del artículo propuesto, figuraba con el número 10 en el proyecto y se ubicaba en el Título II, del Capítulo III, denominado «De la formación y promulgación de las leyes». Su texto era el siguiente:

Articulo No. 10.- Hay acción popular ante el Poder Judicial, contra los reglamentos y decretos gubernativos de carácter general que infrinjan la Constitución o las leyes, sin perjuicio de la responsabilidad política de los Ministros. ${ }^{29}$.

De la lectura de las páginas 2639 a la 2641 del Diario de Debates del Congreso Constituyente de 1931, se aprecia el debate que sostuvieron los congresistas Juan José Hidalgo, Arca Parró, Gamarra, Bustamante de la Fuente, Castro Pozo, Tirado y Revilla, en torno al artículo propuesto por la Comisión de Constitución, debate del cual se desprende que a instancias del señor Hidalgo se incorporó a las "resoluciones" dentro del mismo, pero no fueron atendidas sus propuestas que buscaban incorporar también a los reglamentos y decretos de carácter local, así como señalar que además de la responsabilidad política de los ministros, debía incluirse la responsabilidad civil y criminal.

Es curioso observar que el Congreso Constituyente de 1931 trató el tema de la incorporación del control difuso de constitucionalidad, con motivo de la discusión del dictamen en minoría presentado por la Comisión de Constitución en la sesión del 5 de agosto de 1932, bajo las firmas de los congresistas Feijóo Reina, Francisco Pastor y N.S. Bara Cadillo, en el que se recogían las recomendaciones de la Comisión Villarán y se incluía como artículo 21 el siguiente texto:

Articulo 21‥- La Corte Suprema al conocer los fallos civiles y criminales, está facultada para no aplicar las leyes y resoluciones que juzgue contrarias a la Constitución. ${ }^{30}$ 
En el citado Diario de Debates, en la sesión correspondiente al sábado 6 de agosto de 1932 se produjo el debate sobre el artículo transcrito, en el cual el señor Feijóo Reina efectuó la sustentación respectiva, reproduciendo los argumentos de la Comisión Villarán; siendo del caso resaltar que, después del debate del martes 18 de octubre de 1932, finalmente, la propuesta fue desestimada.

Para concluir la referencia a la incorporación de la acción popular en la Constitución de 1933, debe enfatizarse que, sin lugar a dudas, se trató de un significativo avance en el desarrollo de los instrumentos de control de la constitucionalidad; por cuanto, si bien es cierto que no se trataba, en puridad, de una herramienta directa de control de constitucionalidad, subyacía en ella dicho control si se tiene en cuenta que el examen de legalidad encierra un examen de constitucionalidad. De toda forma fue un avance digno de destacar, aunque lo lamentable es que pasaron muchos años para que se dictaran las disposiciones legales reglamentarias y, curiosamente fue un gobierno de facto el que treintitrés años después, a través del Decreto Ley No. 14605, denominado Ley Orgánica del Poder Judicial, estableciera la vía procesal para el ejercicio de la acción popular, en los términos siguientes:

Articulo $7^{\circ}$.- La acción que concede el artículo 133 de la Constitución se ejercitará ante el Poder Judicial y se substanciará por la vía ordinaria, como proceso de puro derecho, con intervención del Procurador General de la República en representación del Estado. ${ }^{31}$

\subsection{El control disperso de constitucionalidad en el Código Civil de 1936}

El debate llevado a cabo en 1923 en la Comisión Reformadora del Código Civil, al cual se ha hecho referencia anteriormente, tuvo sus frutos recién el año 1936 al promulgarse el Código Civil, en cuyo artículo XXII del Título Preliminar se introdujo dicho texto, con muy ligeras variaciones quedando en definitiva como sigue:

"Cuando hay incompatibilidad entre una disposición constitucional y una legal se prefiere la primera». ${ }^{32}$. 
Se había dado un gran paso: el expreso reconocimiento del control disperso de constitucionalidad. Pero, a su vez, existía un gran vacío: la ausencia de disposiciones procesales que señalaran el camino a seguir para objetivar tal control. Ese vacío fue llenado, recién, veintisiete años después y, paradójicamente, por el mismo gobierno militar que reglamentó el ejercicio de la acción popular; toda vez que en el artículo 8 del Decreto Ley No. 14605, Ley Orgánica del Poder Judicial, de fecha 25 de julio de 1963, textualmente se estableció:

Artículo $8^{\circ}$.- Cuando los Jueces o Tribunales, al conocer de cualquier clase de juicios, encuentren que hay incompatibilidad entre una disposición constitucional y una legal, preferirán la primera.

Si no fueran apeladas las sentencias de Primera Instancia en que se aplique este precepto, se elevarán en consulta a la Primera Sala de la Corte Suprema.

Las sentencias de segunda instancia, se elevarán en consulta a la Primera Sala de la Corte Suprema, si no se interpusiese recurso de nulidad.

Los Jueces y Tribunales no aplicarán los decretos y reglamentos del Poder Ejecutivo o de cualquier otra autoridad contrarios a la Constitución o a las leyes. ${ }^{33}$.

Prácticamente se trata de una reproducción del artículo 142 del texto del proyecto de Constitución de la Comisión Villarán de 1931. Los esfuerzos de los precursores peruanos del control disperso de constitucionalidad, aunque tardíamente y en circunstancias en que el país atravesaba por un momento de ruptura del orden constitucional, habían dado resultado; por lo menos, a nivel normativo.

\section{El control de constitucionalidad a partir de la Constitu- ción de 1979}

\subsection{Consideraciones previas}

Como en alguna medida se ha adelantado, es recién en la Constitución Política de 1979 en que se produce el avance mas notable que registra 
la historia constitucional del Perú, en cuanto al control de constitucionalidad, en razón que en dicho cuerpo normativo se eleva, por primera vez, a nivel de texto constitucional el control disperso o difuso de constitucionalidad y se inaugura el control concentrado de constitucionalidad, con la creación del entonces denominado Tribunal de Garantías Constitucionales; dando origen a lo que, en un primer momento, diversos constitucionalistas peruanos y algunos extranjeros denominaron un Sistema Mixto y que, posteriormente, Domingo García Belaunde llamara Sistema Dual o Paralelo.

Lamentablemente, este avance en el plano normativo constitucional no fue acompañado de una praxis constitucional paralela. Sin embargo y a pesar de los esfuerzos de quienes, a contrapelo de la doctrina contemporánea que ilumina al Derecho Constitucional, aún no creen en las bondades del control de constitucionalidad y, especialmente, del concentrado, la Carta de 1993 ha recogido también ambos sistemas; reproduciendo casi con total exactitud el esquema de la Constitución de 1979. Por ello y a los efectos de un tratamiento mas ordenado de los mismos, se revisarán a continuación, con atención primero en el control disperso de constitucionalidad y, luego, en el control concentrado, en cada una de las citadas constituciones, a fin de ir efectuando una adecuada aproximación al tema central, que es materia del tercer capítulo; esto es: el Tribunal Constitucional peruano como supremo intérprete de la Constitución.

\subsection{El control disperso de constitucionalidad en la Carta de 1979}

Como bien conceptúa César Landa, la historia constitucional peruana se caracteriza por una suerte de prodigalidad en la producción de textos constitucionales, así como lo que el denomina "...la incorporación nominal de modernas instituciones democráticas,... ${ }^{34}$, a despecho de una ausencia de creación de una conciencia sobre la importancia y transcendencia de la Constitución y de sus instituciones; a lo que habría que agregar, en una continuación, aunque menos marcada y ya debilitada, de los problemas del divorcio entre el Estado nación y la sociedad que se presentan desde la fundación de la República. En esta línea, Landa agrega con acierto: 
«Podría señalarse que el desfase de la falta de vigencia de los textos constitucionales en la vida social, se debe a que la expedición de estas cartas políticas se ha dado al unísono de los cambios políticos y sociales de cada época: unos mas estructurales, como la Independencia y el establecimiento de la república y, otros mas coyunturales, como las guerras civiles, las guerras internacionales y las revoluciones civiles y militares. ${ }^{35}$.

A esta realidad no escapó la Constitución de 1979. Nació en verdad sin haber sido pedida por el pueblo peruano ni requerida por sector significativo alguno de la colectividad nacional. Fue consecuencia de una condición impuesta por la dictadura instalada en el país desde el 3 de octubre de 1968, para devolver el poder a la civilidad.

El 28 de julio de 1978 se llevó a cabo la ceremonia de instalación de la Asamblea Constituyente, electa para dictar la nueva Constitución, y el 11 de setiembre de 1978 se nombró en sesión plenaria la Comisión Principal de Constitución, con el encargo de preparar un proyecto de Constitución, que, posteriormente, se sometería al Pleno, para cuyo efecto se le encomendó recopilar y recoger la información respectiva, así como consolidar el trabajo de las diversas Comisiones Especiales, que fueron catorce, y sub comisiones, que tuvieron a su cargo el estudio de las propuestas y la elaboración de los planteamientos puntuales que iban a incorporarse en la nueva Constitución. Dicha Comisión Principal de Constitución estuvo presidida por don Luis Alberto Sánchez

La Comisión Principal de Constitución de la Asamblea Constituyente que aprobó la Constitución de 1979 tuvo veinticinco miembros y su conformación fue multipartidaria. En palabras del propio Luis Alberto Sánchez, contenidas en el prólogo fechado el 12 de setiembre de 1985, a la publicación del Diario de Debates de la Comisión Multipartidaria que elaboró el proyecto de Constitución de 1979:

«...la Constitución de 1979 es realmente pluralista y aprobada por consenso, sin que ningún partido pueda jactarse de que sus ideas sean predominantes. Las combinaciones de votos fueron muy variadas tanto en el seno de la Comisión como en las sesio-

caso peruano». En Pensamiento Constitucional. Lima, Maestría en Derecho con mención en Derecho Constitucional y Fondo Editorial de la Pontificia Universidad Católica del Perú, 1995. p. 73.

35 Loc. cit. 
nes plenarias. Puede afirmarse que imperó una productiva libertad de conciencia para aprobar cada uno de los artículos. $\rangle^{36}$.

Conteniendo el Diario de los Debates de la Comisión Principal los criterios que inspiraron a cada uno de los artículos de la Carta Fundamental de 1979, un estudio riguroso de la racionalidad que llevó a su Legislador Constituyente a elevar a categoría constitucional el control disperso de constitucionalidad, ya consagrado en el Perú desde 1936, a través del artículo XXII del Código Civil de aquel año, obliga a su revisión; dejando constancia que fueron también sumamente importantes los trabajos de las sub comisiones que apoyaron a la citada Comisión Principal de Constitución, para la presentación del proyecto final y la revisión de los artículos que fueron reservados o rechazados inicialmente por el Pleno.

El arribo a la fórmula final consagrada en su artículo 236 , que se transcribe a continuación y que significó elevar a categoría constitucional el control disperso de constitucionalidad, no fue tan lógico y sencillo como podría pensarse, si se tiene en cuenta que la fórmula venía consagrada in fine desde el Código Civil de 1936:

«En caso de incompatibilidad entre una norma constitucional y una legal ordinaria, el Juez prefiere la primera. Igualmente, prefiere la norma legal sobre toda otra norma subalterna.. ${ }^{37}$.

Ciertamente, es curioso observar que ni en la Ponencia de la Comisión Especial No. 3 sobre "Derechos y Deberes Fundamentales. Garantías ${ }^{38}$, ni en Ponencia de la Comisión Especial No. 6 sobre «Poder del Estado-Judicial ${ }^{39}$, ni en las Ponencias presentadas por el Partido Aprista Peruano $^{40}$, el Partido Demócrata Cristiano ${ }^{41}$, el Partido Popular Cristia-

\footnotetext{
36. Comisión Principal de Constitución de la Asamblea Constituyente (1978-1979). Diario de Debates. Lima, Editora Atlantida S.A., 1985, Tomo I. Con prólogo del señor Luis Alberto Sánchez, Presidente de la Comisión Principal de Constitución de la Asamblea Constituyente y Presidente del Senado.

37 García Belaunde, Domingo, con la colaboración de Gutifrrez Camacho, Walter. Op. cit. p. 236.

38 Comisión Principal de Constitución de la Asamblea Constituyente (1978-1979). Op. cit., p. 213

3.) Ibid., Tomo III. p. 155.

40 Ibid., p. 160.

41 Ibid., p. 171.
} 
no ${ }^{42}$, ni en los proyectos del Partido Comunista ni del Partido Socialis$\mathrm{ta}^{43}$, ni en la propia Comisión Principal de Constitución en un primer momento, se planteó la fórmula del control disperso de constitucionalidad en los términos en que finalmente quedó consagrada en el antes citado Artículo 236: la facultad de los jueces de inaplicar una norma por causal de inconstitucionalidad o ilegalidad, en los casos materia de su juzgamiento, cuando entre el derecho invocado por las partes existe un choque normativo (una incompatibilidad) entre una norma constitucional y una legal ordinaria o entre una norma legal ordinaria y una norma subalterna, respectivamente.

En el planteo inicial de la Sub Comisión de Poder Judicial, que integraron los asambleístas Vega García, Valle Riestra, Roger Cáceres Velásquez y Francisco Chirinos Soto, se presentó y aprobó el siguiente texto:

«Cuando un juez o tribunal considere inconstitucional una ley de cuya validez depende el fallo, suspenderá el procedimiento y planteará la cuestión por escrito motivado ante el Tribunal Constitucional.»44.

Como se desprende del mismo, no se trataba del control clásico de constitucionalidad al estilo del modelo americano, disperso o difuso; sino de una figura distinta, en cuya virtud al detectar el juez una ley de cuya validez depende el fallo, que considerara inconstitucional, debía suspender el procedimiento y recurrir ante el Tribunal Constitucional en consulta. Vale decir, no fallaba inaplicando la ley inconstitucional. Sólo suspendía el trámite del litigio, planteaba la cuestión de inconstitucionalidad y se abstenía de seguir interviniendo hasta que el Tribunal Constitucional se pronunciara.

Posteriormente, en la Sesión No. 24 de la Comisión Principal, realizada el martes 27 de febrero de 1979, aparece dentro del Capítulo IV, Poder Judicial, como artículo 239 el siguiente texto, que después se ubicaría como numeral 240 .

"Cuando un juez o tribunal considere inconstitucional una ley de cuya validez depende el fallo, se abstendrá de pronunciar 
sentencia y planteará la cuestión mediante escrito motivado ante el Tribunal de Garantías Constitucionales. ${ }^{45}$.

Nótese que se mantenía el mismo criterio, pero con las únicas diferencias que ya no se hablaba de suspensión del procedimiento, sino de abstención de emitir sentencia, y de Tribunal de Garantías Constitucionales, en vez de Tribunal Constitucional.

En circunstancias en que el texto del artículo 240 ya había sido aprobado por la Comisión Principal de Constitución, en la Sesión No. 27 del viernes 23 de marzo de 1979, el asambleísta Javier Valle Riestra propuso suprimirlo y "...mantener la norma que un juez debe preferir la norma constitucional a la legal, la forma consuetudinaria, clásica, existente en nuestra legislación. $\rangle^{46}$, argumentando que su aplicación ocasionaría que los procedimientos se atasquen; pedido al cual se sumaron los asambleístas Enrique Chirinos Soto y Ortiz de Zevallos

El artículo quedó suprimido, pero en la Sesión No. 55, del 28 de mayo de 1979, aparece como texto del artículo 242 el siguiente:

"En caso de que el juez deje de aplicar una ley por considerarla incompatible con una norma constitucional, la sentencia debe ser elevada en consulta a la Corte Suprema. La Corte Suprema para resolver elevará previamente el asunto al Tribunal de Garantías Constitucionales para que se pronuncie sobre la inconstitucionalidad de la ley. ${ }^{47}$.

En aquella sesión, el asambleísta Enrique Chirinos Soto se opuso a este nuevo texto; oposición a la cual se sumaron los asambleístas Aramburú, Vega, Cáceres Velásquez y Valle Riestra; lográndose finalmente consenso en que se sustituya por el siguiente texto:

"Cuando hay incompatibilidad entre una disposición constitucional y una legal, el juez prefiere la primera. En igual forma procede entre una ley y otra norma de inferior jerarquía. $»^{48}$.

Este texto, con ligeros ajustes de redacción, es el que finalmente fue 
aprobado por el Pleno y quedó consagrado por tanto a nivel constitucional el control disperso de constitucionalidad.

\subsection{El control disperso de constitucionalidad en la Carta de 1993}

La Constitución peruana de 1993 ha mantenido el sistema de control disperso de constitucionalidad, consagrando en el segundo párrafo de su artículo 138 una norma casi idéntica a la que contenía el numeral 236 de su antecesora, que reza:

«En todo proceso, de existir incompatibilidad entre una norma constitucional y una norma legal, los jueces prefieren la primera. Igualmente, prefieren la norma constitucional sobre toda otra norma de rango inferior. ${ }^{49}$.

Contrariamente a lo ocurrido en el caso de la Carta Fundamental de 1979, el Constituyente de 1993 reveló que, desde un primer momento, tuvo clara la idea del control disperso de constitucionalidad, así como su intención de mantenerlo mediante una norma de rango constitucional. Así se desprende desde el denominado "Primer Documento-El Anteproyecto en estado de elaboración ${ }^{50}$, que la Comisión de Constitución del Congreso Constituyente Democrático, presidida por el jurista Carlos Torres y Torres Lara, publicara en el diario oficial El Peruano el día 20 de mayo de 1993 y que constituyó el primer anteproyecto integral y consolidado de los artículos aprobados por la mencionada comisión al 18 del mismo mes; pasando por el llamado "Proyecto Constitucional elevado al Pleno. Dictamen en Mayoria ${ }^{51}$, que fuera publicado en el diario oficial El Peruano y que recogió los cambios efectuados entre el 10 de junio y el 1 de julio de"1993; hasta el denominado "Dictamen Constitucional de la Comisión de Redacción ante el Plenos" ${ }^{-2}$, de fecha 1 de setiembre de 1993, que recogió los cambios efectuados entre el 1 de julio y el 1 de setiembre de 1993.

En el primero de los citados documentos (el anteproyecto consolida-

49 Torres y Torres Lara, Carlos. La nueva Constitución del Perú 1993: antecedentes, fundamentos e historia documentada. Lima, Desarrollo y Paz, 1993 p. 109.

so) Ibid., pp. 239-307.

si Ibid., pp. 329-373.

52 Ibid., pp. 419-480. 
do al 18 de mayo de 1993), en la parte relativa al control constitucional y administrativo se incluyó un artículo exactamente igual al numeral 236 de la Constitución de 1979, cuyo texto era el siguiente:

«En caso de incompatibilidad entre una norma constitucional y una norma legal ordinaria, el juez prefiere la primera. Igualmente, prefiere la norma legal sobre toda otra norma de menor jerarquía. ${ }^{53}$.

En el tercero de los citados documentos (el Dictamen Constitucional de la Comisión de Redacción del 1 de setiembre de 1993), en la parte relativa al Poder Judicial y como segundo párrafo del artículo 148 se encuentra el siguiente texto:

«En todo proceso, de existir incompatibilidad entre una norma constitucional y una norma legal, los jueces prefieren la primera. Igualmente, prefieren la norma legal sobre toda otra norma de rango inferior. $\gg^{54}$.

Como se observa, este fue el texto que, concluídos los reajustes y efectuados los recortes, se consagró como segundo párrafo del numeral 138 que se ha transcrito líneas arriba y que está actualmente vigente.

En lo que atañe al control disperso de constitucionalidad en la Carta de 1993 queda claro, en consecuencia, que éste ha sido ratificado y, en alguna medida perfeccionado, ya que el análisis comparativo entre el texto de la Constitución de 1979 (artículo 236) y el de esta última (artículo 138), revela que en la Constitución de 1993 se ha precisado que el control disperso de constitucionalidad se ejerce en "todo proceso», lo cual viene a enfatizar la obligación del juzgador de velar por la constitucionalidad y también por la legalidad en todos los casos en que interviene, haciendo un análisis de las normas invocadas por las partes, para, independientemente de que aquellas lo hayan invocado o no, preferir la norma constitucional o la norma legal, según el caso. 


\subsection{El control concentrado de constitucionalidad en la Constitución de 1979: El Tribunal de Garantías Cons- titucionales}

Tal como se ha mencionado anteriormente, en la Constitución de 1979 se dieron dos avances notables en lo que atañe al control de constitucionalidad. El primero, consistente en la elevación a rango constitucional del control disperso de constitucionalidad. El segundo, consistente en la inauguración del control concentrado de constitucionalidad, a través de la creación del entonces denominado Tribunal de Garantías Constitucionales. Este segundo avance fue el mas importante y novedoso. Inédito hasta ese momento; excepción hecha de la modalidad sui géneris de control de decretos y reglamentos de carácter general, que venía consagrada en el numeral 133 de la Carta de 1933 y que, como se ha visto, recién fue reglamentada a través de la Ley Orgánica del Poder Judicial del 25 de julio de 1963.

El examen, tanto del Diario de Debates de la Comisión Principal de Constitución, como de las comisiones especiales, de las sub-comisiones y del Pleno, correspondientes a la Asamblea Constituyente que elaboró la Constitución de 1979, revela que no existió desde un primer momento la idea de consagrar un control concentrado de constitucionalidad; sino, por el contrario, de mantener la tesis tradicionalmente recogida en las constituciones anteriores, de considerar al Poder Legislativo como el gran guardián de la constitucionalidad.

La incorporación del control concentrado de constitucionalidad en la Carta de 1979 fue consecuencia de un proceso lento, complicado y de ardua confrontación, en el cual, en honor a la verdad jugó un papel preponderante el asambleísta Javier Valle Riestra, quien se constituyó en el propulsor de esta conquista del Derecho Constitucional peruano.

En la ponencia de la Comisión No. 3, presentada el 27 de octubre de 1978 por los asambleístas Mario Polar, Javier Valle Riestra, Carlos Roca, Luis Heysen, Alfonso Ramos, Pedro Cáceres y Magda Benavides, al presidente de la Comisión Principal de Constitución, en la parte relativa a las Garantías, se lee textualmente:

«En el mismo Título, aunque sin precisar sus características, hemos incluido un precepto relativo a la creación de un Tribunal de Garantías Constitucionales. Este artículo necesariamente deberá ser concordado por la Comisión Principal con las iniciativas 
que sobre el particular formule la Comisión Encargada de presentar una ponencia sobre el Poder Judicial. ${ }^{55}$.

Más adelante, en la misma ponencia, en el articulado propiamente dicho se incluyen dos cuyos textos son los siguientes:

Artículo.-Se constituye un Tribunal de única instancia denominado de Garantías Constitucionales y que es competente para conocer:

a) De la acción de Hábeas Corpus;

b) De la acción de amparo;

c) De la inconstitucionalidad de las leyes, sea en vía de acción o de excepción;

d) De la inconstitucionalidad de decretos, reglamentos, resoluciones supremas, resoluciones ministeriales, resoluciones legislativas o fallos judiciales que transgredan la Constitución o las leyes. ${ }^{56}$.

Artículo.- Una ley regulará la estructura y procedimiento del Tribunal de Garantías Constitucionales. ${ }^{57}$.

La idea ya había sido plasmada pero tendría que recorrerse un largo camino para arribar a la fórmula que finalmente se consagró, por cuanto surgieron varias posiciones discrepantes, desde las que rechazaban totalmente la idea de crear un ente de control concentrado de la constitucionalidad, con autonomía e independencia respecto de los poderes del Estado, hasta la de otorgar el control concentrado a la Corte Suprema de la República, como fue la del Partido Aprista Peruano, contenida en el proyecto alcanzado a la Comisión Principal de Constitución, como parte de la ponencia de la Comisión Especial No. 6, sobre Poder del Estado-Judicial. En aquella ponencia, en la parte relativa a las atribuciones constitucionales, si bien se hace referencia a que las mismas conllevan "...la labor de cautelar la supremacia de las normas constitucionales. ${ }^{5 \times}$, se estima que ésta debe corresponder al máximo tribunal de justicia de la nación: la Corte Suprema de la República.

55. Comisión Principal de Constitución de la Asamblea Constituyente (1978-1979). Op. cit., Tomo I. p. 215.

sh Ibid., p. 225.

57 Loc. cit.

s. Ibit., Tomo III. p. 160. 
En resumen, como bien lo señalara el asambleísta Vega García, en cuanto a las atribuciones constitucionales, se inclinaron por la creación de un Tribunal de Garantías Constitucionales el Partido Popular Cristiano, el Partido Socialista Revolucionario y el Partido Demócrata Cristiano; mientras que el Partido Aprista atribuyó tales facultades a la Corte Suprema ${ }^{54}$.

En la Sesión No. 22 de la Comisión Principal de Constitución, llevada a cabo el 14 de febrero de 1972, en circunstancias en que se había producido en sesiones anteriores una confrontación de ideas entre los asambleístas Francisco Chirinos Soto, quien sustentó la ponencia aprista, de entregar el control concentrado de constitucionalidad a la Corte Suprema, y la tesis de Javier Valle Riestra de crear un ente autónomo e independiente, este último presentó un proyecto sobre el Tribunal de Garantías Constitucionales, cuya fundamentación interesa transcribir, siguiendo exactamente el texto que aparece en el acta en cuestión:

«El señor VALLE RIESTRA.- Voy a hacer un esbozo de este proyecto de Tribunal de Garantías Constitucionales, recordando que el Tribunal ya existe en Alemania, en Italia, en Francia y que existe varios sistemas, dentro de ellos la declaración de anticonstitucionalidad a priori y a posteriori, cuando por acción o por excepción llega a conocimiento del Tribunal una cuestión constitucional antes de que se pronuncie sobre la misma. Después, la trascendencia de la resolución del tribunal o es simplemente declarativa como la que existe en la legislación italiana que del momento que se publica la resolución del tribunal en el Boletín oficial del Estado, dicha resolución queda abrogada, o es el problema final de si tiene efectos retroactivos ultraactivos dicha decisión final.

Entonces este Tribunal de Garantías tal como lo diseño en el proyecto que tengo aquí, se comprondría de 12 miembros: dos designados por la Federación Nacional del Colegio de Abogados, dos por el Conscjo Nacional de la Magistratura, dos por el Senado, dos por la Cámara de Diputados, dos por la Corte Suprema y dos por las Facultades de Derecho. Para ser miembro de este tribunal se requerirían las condiciones exigidas para ser magistrado supremo y su personal debe ser escogido entre magistrados, fiscales, profesores universitarios de Derecho, abogados de reconocida 
competencia y trayectoria y sobre todo de línea en defensa de los Derechos Humanos, requisito éste que exige actualmente el Tribunal Nacional español. Como atribuciones se le señala a este tribunal una jurisdicción en todo el territorio de la República y competencia para declarar la anticonstitucionalidad de las leyes y resoluciones del Congreso, así como de los decretos, reglamentos y resoluciones del Poder Ejecutivo y la de los entes públicos; declarar-aqui pongo- en vía de casación. Ya que se ha insistido tanto en introducir la casación, en este carácter podría ensayarse: declarar en vía de casación la inconstitucionalidad de las resoluciones judiciales definitivas a solicitud del Fiscal General de la Nación. E insistido en este punto de vista ya había un conato de cambio de ideas en sesión anterior con el doctor Chirinos, cuando yo explicaba mi convicción de que no sólo es anticonstitucional una ley, no sólo es anticonstitucional un reglamento del Poder Ejecutivo, sino también las decisiones de los tribunales, claro que se refieren a pleitos entre partes. Pero hay que ver hasta que punto no es aceptado en el orden público si ahí se permite que subsista una violación de la Constitución, de las leyes, de los Derechos Humanos. La Ley de Garantías Constitucionales Española de 1932-33, recogía la posibilidad en vía de amparo de combatir la anticonstitucionalidad de una resolución judicial y también la tiene la Constitución mexicana.

Ahora, para evitar un abuso, para evitar la alteración de la cosa juzgada, se tramitaría a través del Fiscal de la Nación, que ya hemos estructurado, ¿no es cierto? Se recurriría al Fiscal diciendo que en tal resolución, recaída en un pleito seguido por $\mathrm{A}$ con $\mathrm{B}$, se ha violado la Constitución. El Fiscal si lo considera así, podría tramitarla si fuera realmente algo lesivo al orden público.»" ${ }^{60}$.

Este fue el esbozo que permitió entrar de lleno al modelo consagrado en la Carta de 1979. Empero, su adopción definitiva, así como sus competencias, el número de sus miembros, el tiempo de su mandato y los titulares de la acción de inconstitucionalidad fueron largamente debatidos, tal como aparece de los Tomos IV, V, VII y VIII del Diario de Debates de la Comisión Principal; debiendo destacarse que en el proyecto de Constitución que elevara el Presidente de la Comisión Principal de Constitución, con fecha 27 de marzo de 1979, al Presidente de la 
Asamblea Constituyente don Víctor Raúl Haya de la Torre, en la parte relativa a las garantías, se expresa que:

«...se crea un Tribunal integrado por doce miembros, entre los cuales seis son designados por los tres poderes del Estado.

Su finalidad primordial es declarar la inconstitucionalidad en todo o en parte de cualquier acto legislativo o de la administración pública. Además conocerá de los autos denegatorios de hábeas corpus y del amparo, agotada la vía judicial; de las apelaciones contra resoluciones que destituyan a los magistrados; de la resolución de la Corte Nacional de Elecciones que anula el proceso electoral nacional.

Resolverá conflictos de competencia entre el Poder Central y los órganos departamentales y regionales y absolverá consultas sobre constitucionalidad de tratados pendientes de ratificación o adhesión» ${ }^{61}$.

El articulado propuesto para regular lo atinente a este ente de control concentrado de la constitucionalidad, es bastante elocuente para comprobar en que medida el planteamiento del asambleísta Javier Valle Riestra llegó a calar entre los demás miembros de las comisiones encargadas, ya que se comprendió dentro de sus características y competencias algunas que no llegaron a aprobarse, tales como la de "Conocer en apelación de las resoluciones que expida el Consejo Nacional de la Magistratura que imponga destitución a magistrados de cualquier categoria;...", la de "Resolver en via de apelación en el plazo máximo de siete dias naturales, la resolución de la Corte Nacional de Elecciones que anule el proceso electoral nacional;...", la de "Resolver conflictos de competencia entre el Poder Central y los órganos departamentales y regionales asi como de éstos entre si;..." y la de "Absolver consultas del Presidente de la República o del Congreso sobre la constitucionalidad de los tratados internacionales pendientes de ratificación o de adbesión. ${ }^{62}$.

Sin embargo, posteriormente se produjo un significativo recorte, como consecuencia del debate producido a nivel de la Comisión Principal de Constitución, sobre todo a instancias del asambleísta Ernesto Alayza Grundy, quien fue sumamente duro al cuestionar la amplitud de facultades que se le pretendía atribuir, argumentando que se estaba des- 
naturalizando la función del Tribunal de Garantías Constitucionales $s^{63}$, a pesar de la ardorosa defensa efectuada por el asambleísta Valle Riestra. Así, paulatinamente, a instancias del propio Alayza Grundy, de Aramburú Menchaca, de Sotomarino y de Ramírez del Villar, entre otros, se fueron limitando las competencias del Tribunal de Garantías Constitucionales, hasta arribar a la fórmula final:

«1.- Declarar, a petición de parte, la inconstitucionalidad parcial o total de las leyes, decretos legislativos, normas regionales de carácter general y ordenanzas municipales que contravienen la Constitución por la forma o por el fondo; y

2.- Conocer en casación las resoluciones denegatorias de la acción de hábeas corpus y la acción de amparo agotada la vía judicial.» ${ }^{64}$.

Por lo demás, se precisó que dicho tribunal era el órgano de control de la Constitución (debió decirse de la constitucionalidad), que se componía de nueve miembros (tres designados por el Congreso, tres por el Poder Ejecutivo y tres por la Corte Suprema), se mantuvieron en esencia los requisitos exigidos, se estableció la renovación por tercios cada dos años, la reelección de sus miembros, la ausencia de mandato imperativo, la independencia por sus votos y opiniones, el privilegio de no ser denunciados ni detenidos durante su mandato, se precisaron los titulares de la acción de inconstitucionalidad, que sus sentencias no tenían efecto retroactivo, el procedimiento de efectivización de las sentencias y el que una ley orgánica regularía su funcionamiento.

No se pretende en esta investigación ahondar mas en el tema del Tribunal de Garantías Constitucionales, bastando decir que la Ley No. 23385, del 3 de mayo de 1982, denominada Ley Orgánica del Tribunal de Garantías Constitucionales, reguló su organización y atribuciones, así como diversos aspectos relacionados a su funcionamiento, incluyendo entre ellos el procedimiento para la declaración de inconstitucionalidad y para la casación de las resoluciones denegatorias de hábeas corpus y amparo.

A pesar de las buenas intenciones del Legislador Constituyente de la Carta de 1979, siguiendo a César Landa ${ }^{65}$, la evaluación del funciona-

\footnotetext{
6.3 Ibid., Tomo VII. p. 562.

ot Garcia Brafunde, Domingo, con la colaboración de Gutierrez Camacho, Walter. Op. cit., p. 487.

6.5 Landa Arromo, César. Op. cit., p. 80.
} 
miento del Tribunal de Garantías Constitucionales en el período comprendido entre el 19 de noviembre de 1982 fecha en que se produjo su instalación, y el 5 de abril de 1992, fecha en que fue clausurado por el autogolpe del presidente Alberto Fujimori, arroja un resultado francamente decepcionante, si se tiene en cuenta que, en lo que atañe al control concentrado de constitucionalidad, de las más de 25 acciones de inconstitucionalidad interpuestas durante los diez años de su funcionamiento, sólo se resolvieron 15 , no obstante la frondosa legislación dictada en ese período de tiempo, que comprendió leyes, decretos legislativos, normas regionales de carácter general y ordenanzas municipales. En buena cuenta, el Tribunal de Garantías Constitucionales abdicó de su función y, en modo alguno, ejerció un real control concentrado de constitucionalidad y, menos aún, actuó como supremo intérprete de la Constitución.

Con respecto a este último aspecto, conviene resaltar que de la documentación revisada no aparecen mayores luces sobre la posición del legislador en torno a la estimación o no que fuera considerado como intérprete supremo de la Constitución; situación que no resulta extraña si se tiene en cuenta la resistencia que, desde los inicios de la República, han mostrado los Legisladores Constituyentes en torno al tema.

\subsection{El control concentrado de constitucionalidad en la Constitución de 1993}

En el denominado "Primer Documento-Anteproyecto en estado de elaboración ${ }^{606}$, que hizo publicar la Comisión de Constitución del Congreso Constituyente Democrático en el diario El Peruano no aparece contemplada la figura de un ente de control concentrado de constitucionalidad, ajeno e independiente de los otros órganos del Estado y con autonomía, como era (por lo menos a nivel normativo constitucional) el fenecido Tribunal de Garantías Constitucionales, lo cual revela que, desde un inicio, la intención del Legislador Constituyente de la Carta de 1993 fue eliminarlo o, en todo caso, realizar un planteo distinto al consagrado en la Constitución de 1979. Esta hipótesis se reafirma si se tiene en cuenta que en el citado documento, en la parte relativa al control constitucional y administrativo, y numerados como artículos 2 y 3 , se encuentra los siguientes textos:

6o Torres y Torrts Lara, Carlos. Op. cit., pp. 239-309

6.7 Ibid., p. 286. 
Artículo 2.- El Poder Judicial es el órgano de control de la Constitución.

Los procesos de hábeas corpus y amparo se tramitan en dos instancias. Contra las resoluciones denegatorias procede recurso de casación por ante la Corte Suprema de Justicia. ${ }^{67}$.

Articulo 3.- Compete al Poder Judicial conocer de la acción popular por infracción de la Constitución o de la ley, contra los reglamentos, las resoluciones y decretos de carácter general que expidan el Poder Ejecutivo, los gobiernos regionales y locales y demás personas de derecho público.

El Poder Judicial ejerce el control constitucional o legal de cualquier resolución de la administración pública que causa estado. Para iniciar el proceso respectivo se debe agotar la vía administrativa. La ley determina las reglas de competencia. ${ }^{68}$.

Como se observa, tanto en la primera parte del citado artículo 2 como en la segunda parte del también citado artículo 3, aparece una asignación expresa e inequívoca del control de la constitucionalidad (mal denominado control de la Constitución) al Poder Judicial. Por lo demás, esta posición se reafirma si se tiene en cuenta que en el artículo 220 del proyecto de Constitución, elevado al Pleno como dictamen en mayoría por la Comisión Principal de Constitución del Congreso Constituyente Democrático, con los cambios efectuados entre el 10 de junio y el 1 de julio de 1993, se estableció literalmente:

«La Sala Constitucional de la Corte Suprema es el órgano de control de la Constitución. Ejerce el control constitucional o legal de cualquier resolución de la administración pública que causa estado. Para iniciar el proceso respectivo se debe agotar la vía administrativa. La ley determina las reglas de competencia. ${ }^{89}$.

Se aprecia que, dentro del mismo criterio de asignar el control de constitucionalidad al Poder Judicial, ya se precisa que sería la denominada Sala Constitucional de la Corte Suprema el órgano encargado, en concreto y con facultad específica de realizarlo. En este orden, siguiendo a Jorge Danós Ordoñez y apelando a las fuentes consultadas, cabe

6s. Loc. cit.

69 Ibid., p. 370 . 
reiterar que en las propuestas de la Comisión de Constitución del Congreso Constituyente Democrático, las cuales se difundieron por intermedio del diario El Peruano "...no se contemplaba la existencia de un Tribunal Constitucional, como órgano autónomo al estilo del ex-Tribunal de Garantías Constitucionales". ${ }^{71}$, y que fue recién en el debate del Pleno, que se realizó el 12 de agosto de 1992, en que por insistencia del congresista Carlos Ferrero, en que se propugnó el mantenimiento de un ente de control concentrado de constitucionalidad, con las mismas características del anterior Tribunal de Garantías Constitucionales, al que se denominaría Tribunal Constitucional; postura que finalmente lograra éxito, a pesar de la oposición que encabezó el congresista Enrique Chirinos Soto, quien en reiteradas oportunidades ha formulado duras críticas a este modelo ${ }^{71}$.

Es destacable, para los efectos de la presente investigación la exposición que realizara el congresista Ferrero Costa en la sesión del Congreso Constituyente Democrático del 12 de agosto de 1993, presidida por los señores Jaime Yoshiyama, Gilberto Siura y Víctor Joy Way, en la cual calificó expresamente al tribunal en cuestión como el intérprete supremo de la Constitución:

«El señor FERRERO COSTA llevó a cabo diversos comentarios sobre el Tribunal de Garantías Constitucionales y la acción de cumplimiento. Diferenció el control constitucional de control de la legalidad, y fundamentó la disposición por la que se establece que en los estados de excepción no se suspende el ejercicio de las acciones de hábeas corpus y amparo ${ }^{72}$.

«Asimismo, especificó las funciones del Tribunal de Garantías Constitucionales, considerándolo el intérprete supremo de la Constitución y el titular del pronunciamiento sobre la acción de inconstitucionalidad y de la solución de conflictos entre los órganos de gobierno. ${ }^{73}$.

7) Danós Ordoǹiz, Jorge, "Aspectos orgánicos del Tribunal Constitucional". En Lecturas sobre Temas Constitucionales. No. 10. Lima, Comisión Andina de Juristas, 1994. p. 283.

71 Ibid., p. 284.

72 Congreso Constituyente Democrático. Actas de las sesiones del Plenario-Constitzción Politica de 1993. Lima, Dirección del Diario de los Debates del CCD, s/f. p. 215.

I3. Ibid., pp. 215-216. 
En esta misma línea el congresista Fernández Arce argumentó sobre la necesidad que el tribunal sea un organismo autónomo y diferente del Poder Judicial, sosteniendo que:

«Bien podría ser el intérprete de la Constitución, en cuanto que el interpretador adecuado de la misma no necesariamente debe ser quien la genera, dado que la norma una vez sancionada posee vida propia. ${ }^{74}$.

Como quiera que la referencia específica al Tribunal Constitucional peruano y a la interpretación constitucional se harán en el capítulo siguiente, baste agregar, también coincidiendo con Jorge Danós ${ }^{75}$ que, en términos generales, la Constitución de 1993 ha mejorado la regulación del tribunal, corrigiendo algunos errores e incrementando sus atribuciones; toda vez que, como bien se sabe, el Tribunal Constitucional de la Carta de 1993, además de conocer de la acción de inconstitucionalidad, resuelve los conflictos de competencia o atribuciones cuando de por medio está en juego un órgano de rango constitucional y conoce como instancia de fallo las resoluciones denegatorias de hábeas corpus, amparo, hábeas data y acción de cumplimiento.

\section{El Sub-Modelo Dual o Paralelo imperante en el Perú}

Como se ha visto, la Constitución de 1993 reproduce las normas existentes en la Constitución de 1979 sobre control de constitucionalidad, consagrando tanto el Modelo Disperso como el Modelo Concentrado, a través de sus artículos 138 y 211 , que en sus partes pertinentes preceptúan que:

«En todo proceso, de existir incompatibilidad entre una norma constitucional y una norma legal, los Jueces prefieren la primera. Igualmente, prefieren la norma legal sobre toda otra norma de rango inferior.» (Artículo No. 138, segundo párrafo). ${ }^{76}$.

«El Tribunal Constitucional es el órgano de control de la

\footnotetext{
Loc. cit.

DaNós ORDONitz, Jorge. Loc. cit., p. 284.

Garcia Bi:Launist, Domingo; y Fernánimz Skcialo), Francisco. La Constitución peruana de 1993. Lima, Editora Jurídica "Grijley» E.I.R.L., 1994. p. 178.
} 
Constitución. Es autónomo e independiente. Se compone de siete miembros elegidos por cinco años.» (Artículo No. 201, primer párrafo). ${ }^{77}$

Se mantiene, por tanto, la existencia de ambos sistemas originarios de control de constitucionalidad; es decir, imponiendo a los jueces y magistrados la obligación de preferir la norma constitucional e inaplicar la inconstitucional, cuando al resolver los casos que conocen encuentren una colisión normativa entre un dispositivo de jerarquía constitucional y un dispositivo de jerarquía legal; $y$ facultando al Tribunal Constitucional a conocer, vía la acción de inconstitucionalidad, aquellos casos en que se incurra en vicio de inconstitucionalidad por normas de máxima jerarquía, en las áreas del gobierno nacional, de los gobiernos regionales y de los gobiernos locales.

La coexistencia de estos dos modelos originarios configura el SubModelo Dual o Paralelo actualmente imperante en el Perú.

\section{CAPÍTULO III}

\section{El tribunal constitcional peruano: Intérprete del supremo de la Constitución}

\section{La interpretación constitucional como elemento consustan- cial al análisis de constitucionalidad}

Estando a lo analizado en los capítulos precedentes, corresponde al Tribunal Constitucional Peruano el control de la constitucionalidad de acuerdo al denominado Modelo Europeo, Austríaco, Kelseniano, de Control Ad-Hoc o de Control Concentrado; modelo que, tal como se explicó, fuera ideado por el jusfilósofo Hans Kelsen, inaugurado con la creación en 1919 del Tribunal Constitucional de Austria y reconocido por primera vez a nivel constitucional, en la propia Constitución austríaca de 1920.

Este modelo, como también se adelantó, tiene como principales características la de ser concentrado, abstracto y derogatorio. Ello, en ra- 
zón que un solo órgano detenta la atribución, el poder o la facultad de llevar a cabo el control de constitucionalidad (en muchos casos, en forma exclusiva y excluyente respecto de los otros órganos del Estado), analizando la norma cuestionada en forma aislada (independiente del caso concreto que pudiera haber dado origen a su cuestionamiento) y dejándola sin efecto (con carácter general o erga omnes) si estima que está incursa en causal de inconstitucionalidad.

En este orden, es el Tribunal Constitucional peruano el ente que ejerce el control de constitucionalidad concentrado, abstracto y derogatorio de las normas impugnadas por alguna causal de inconstitucionalidad, sea de forma (cuando no hayan sido aprobadas o promulgadas o publicadas en la forma prescrita por la Constitución) o de fondo (cuando contravengan la Constitución en el fondo); para lo cual debe realizar el análisis de constitucionalidad.

Ahora bien, siendo la constitucionalidad aquel vínculo de armonía y concordancia plena que debe existir entre la Constitución y las demás normas que conforman el sistema jurídico (tanto en cuanto a la forma como al fondo), que conecta o une los postulados constitucionales con sus respectivos correlatos normativos, en sus diversos niveles de especificidad, y que es consustancial al proceso de implementación constitucional e imprescindible para la compatibilidad y coherencia del sistema jurídico; el análisis de constitucionalidad será precisamente el análisis, valga la redundancia, de ese vínculo de armonía y concordancia plena.

Empero, constituyendo en puridad el análisis de constitucionalidad un ejercicio comparativo que parte de descubrir el sentido de la Constitución como un todo y, a partir de ahí, de una o varias de sus partes, para descubrir si el correlato reglamentario materia de cuestionamiento no incurre, desde la forma o el fondo, en desnaturalización, desborde, contradicción o incompatibilidad; tal ejercicio solo es posible a través de la interpretación constitucional.

En otras palabras, como se expresara en el capítulo I, la determinación de la existencia o inexistencia de ese vínculo entre la norma constitucional y la norma reglamentaria (esto es, de constitucionalidad) está ligada al tema de la interpretación constitucional, desde que conociendo a cabalidad el espíritu, los alcances y el auténtico sentido de cada norma constitucional, se podrá establecer si la norma reglamentaria ha mantenido su espíritu, sus mismos alcances y su verdadero sentido; o, si por el contrario, los ha desnaturalizado. Si es constitucional o no.

En tal virtud, la interpretación constitucional es consustancial al análisis de constitucionalidad. Vale decir, le es inherente, forma parte de él; 
a tal punto que no puede haber análisis de constitucionalidad sin interpretación constitucional. Es mas, podría decirse que tampoco puede haber constitucionalidad, conceptualmente hablando, sin interpretación constitucional, desde que aquella implica análisis y éste, a su vez, interpretación, que no es otra cosa que desentrañar el sentido de la Constitución, tanto como norma cuanto como conjunto normativo estableciendo lo que Manuel Aragón denomina «el parámetro de control» y, a partir de ese punto, el sentido de cada uno de sus postulados, lo cual conlleva escudriñar su sentido axiológico, pero siempre por métodos jurídicos.

En cuanto a este punto, es menester dejar aclarado que la Constitución de 1993 al establecer en su artículo 201 que "El Tribunal Constitucional es el órgano de control de la Constitución. ${ }^{2}$, reproduce el error en que se incurrió en la primera parte del numeral 296 de la Carta de 1979, en el que se preceptuaba que "El Tribunal de Garantía Constitucionales es el órgano de control de la Constitución. गे $^{3}$ y que, felizmente, se ha superado con la precisión efectuada en la primera parte del artículo 1ro. de la Ley Orgánica del Tribunal Constitucional No. 26435, que norma que "El Tribunal Constitucional es el órgano de control de la constitucionalidad. $»^{4}$. En efecto, porque, como ha quedado demostrado, lo que controla el Tribunal Constitucional no es la Constitución sino la constitucionalidad.

\section{La necesidad de una adecuada técnica de interpretación constitucional}

Siguiendo al mismo Manuel Aragón es de destacar que:

«...Interpretar es «concretizar», para lo que es preciso «comprender» (Hesse), es decir, comprender la norma dentro de un sistema no sólo normativo sino también de categorías teóricas que le dan significado, que le prestan coherencia. No es posible

\footnotetext{
Aracoon, Manuel. "La interpretación de la Constitución y el carácter objetivado del control jurisdiccional». En Revista Española de Derecho Constitucional. Madrid. Año 6, Número 17, Mayo-Agosto 1986. pp. 87-156.

Garcia Bhlaunde, Domingo, Fervánlohz Shagio, Francisco. La Constitución peruana de 1993 Lima, Editora Jurídica "Grijley», 1994. p. 202.

3 Garcia Belaunde, Domingo, con la colaboración de Gutilrraz Camacho, Walter. Las constituciones dél Perí. Lima, Edición Oficial, 1993. p. 296.
} 
concretizar, no es posible interpretar la norma constitucional (norma abierta, en muchas ocasiones, y que expresa, también en otras, valores sustantivos) sin una previa teoría de la Constitución (Hesse, Dworkin). El intérprete, necesariamente, ha de contar con el bagaje teórico que le facilite la tarea de extraer del precepto jurídico su significado "constitucionalmente adecuado» o de convertir en principios jurídicos los valores enunciados por la norma o de establecer las conexiones pertinentes entre unos y otros principios que concurran en el caso concreto de aplicación. Y esa teoría de Constitución, tan relevante para la interpretación, no puede ser otra que la que descanse en un concepto de Constitución auténtica, esto es, de Constitución democrática, concepto que no puede ser invalidado por el fácil expediente de tacharlo de "político» (90). En el marco de esa teoría encuentra su «objetivación» la tarea interpretadora justamente porque ahí se encuentran las categorías "contrastables" para su ejercicio y los límites jurídicos que impiden la libertad política de "valoración». Hoy, se ha dicho con fortuna, la interpretación es una de las cuestiones fundamentales del Derecho constitucional. Hoy, podría añadirse también, la teoría de la Constitución es, a su vez, la base "firme» de ese Derecho y, en consecuencia, el conocimiento o saber imprescindible para abordar con seriedad y rigor sus problemas y entre ellos el fundamental de la interpretación constitucional. $\aleph^{5}$

Si interpretar es descubrir, en última instancia, el significado "constitucionalmente adecuado ${ }^{6}$ en base a una previa teoría de la Constitución asentada en un concepto de Constitución democrática, que conlleve desentrañar el sentido de la normativa constitucional analizando los valores constitucionales «...de acuerdo a categorias juridicas y no políticas. ${ }^{7}$, es imprescindible entonces contar con una adecuada técnica de interpretación constitucional. Sobre este particular, Luis Carlos Sáchica afirma que:

«La interpretación de las normas constitucionales -no obstante

\footnotetext{
4 Comisión Andina de Juristas. Garantias constitucionales. Legislación pigente. Lima, Conisión Andina de Juristas, 1996. p. 65.

Aracion, Manuel. Op. cit., pp. 127-128.

Loc. cit.

Ibid., p. 129.
} 
su pertenencia al orden jurídico estatal con las demás que lo integran - por razón de su jerarquía, su carácter originario e incondicional y su calidad de fuentes de las otras normas, esto es, por ser normas de normas, o normas de organización del orden jurídico, requicren una técnica interpretativa especial, un tratamiento diferente al de la hermeneútica común.» ${ }^{\$}$

En efecto, como apunta el mismo Sáchica, hay dos circunstancias que peculiarizan la interpretación constitucional: 1) que las normas constitucionales "...no son derivación ni desarrollo de otras superiores que orienten y condicionen su aplicación;.... ; y 2) que el nacimiento de las normas constitucionales:

«...tiene relación inmediata y directa con hechos políticos, históricos y culturales, determinantes de sus tendencias, contenido y finalidades, de su modo de ser prescriptivo, a su vez condicionante de todo el orden normativo del Estado.»11

Además, debe tenerse en cuenta "...la naturaleza especialísima y la estructura excepcional de dichas normas. $»^{11}$, muchas de las cuales son simplemente declarativas y carentes de un carácter normativo, como por ejemplo aquellas que integran la parte dogmática de la Constitución, que vienen a ser desde declaraciones de principios hasta simples enunciados de propósitos, que encierran el proyecto político que ha servido de base al Legislador Constituyente y que sirven de guía axiológica.

Otras son de carácter estructural; determinantes de la forma de ser del Estado, de su estructura propiamente dicha, de su organización, de la forma como está distribuído el poder y de las facultades de cada ente estatal, entre otros importantes aspectos.

A lo dicho hay que sumar que la interpretación constitucional exige para el intérprete una ubicación en el tiempo, con una clara visión del pasado, así como del entorno que rodeó al Constituyente, y con un conocimiento profundo de los diversos factores que determinaron la producción de un determinado texto constitucional. En buena cuenta, un conocimiento que trasciende el simple análisis de la literalidad de la nor-

* Sáchica, Luis Carlos. El Control de constitucionalidad. Bogotá, Editorial Temis S.A., 1988. p. 1.

"Loc. cit.

10) Loc. cit.

11 Ibid., p. 2. 
ma y que permite ir al espíritu que la animó. Como afirma el mismo Sáchica, la interpretación constitucional:

«Impone, a más de la técnica jurídica, amplios conocimientos del derecho, una sensibilidad política, un hondo sentido histórico, una visión del futuro, un severo realismo, una postura humanista, una capacidad creadora y una vigorosa orientación ética no comunes.»12.

\section{Características de la interpretación constitucional}

Cualquier intento de marcar características corre el riesgo de tener una dosis de arbitrariedad o de parcialidad, desde que, por mas rigor que imponga el investigador en su tarea, siempre habrá enfoques, matices o puntos de vista, que impliquen una visualización distinta, sin perjuicio de la dosis de inevitable subjetividad que toda acción humana traduce. Por consiguiente, para evitar caer en tales riesgos, se ha asumido la posición esbozada por el constitucionalista argentino Nestor Pedro Sagüés ${ }^{13}$, que es la que se resume a continuación, la misma que interesa sobremanera por estar elaborada en la consideración de aquella interpretación que debe realizar un Tribunal Constitucional, como intérprete último de la Constitución ${ }^{14}$, y que se deriva de su rango constitucional, así como de la trascendencia de sus decisiones.

\subsection{Interpretación práctica}

Sagüés sostiene que la interpretación práctica es "...una interpretación para la aplicación,... ${ }^{15}$, por cuanto la aplicación propiamente dicha es en realidad una parte del proceso de activación de la norma constitucional; proceso que trasciende y desborda los linderos del análisis puramente académico y toca directamente a los aquí y a los ahora de cada momento, de la realidad misma sobre la que la norma constitucional se

\footnotetext{
$12 \quad$ Ibid., p. 4.

13. SAciÜFS, Néstor Pedro. "Tribunal Constitucional e interpretación constitucional". En Lecturas Constitucionales Andinas. No. 4. Lima, Comisión Andina de Juristas y Fundación Konrad Adenauer. pp. 17-37.

$14 \quad$ Ibid., p. 24.

15 Loc. cit.
} 
aplica. En tal sentido, se trata de una interpretación que, además de "profesional», sea funcional y útil, para "...optimizar las posibilidades de la Constitución para resolver problemas,... $»^{16}$. No para agudizarlos o mantenerlos irresueltos.

\subsection{Interpretación creativa}

Se trata de una interpretación que, sin perder el sentido esencial de la Constitución y de sus diversos preceptos, encierre una dosis de creatividad de cara a las situaciones que exijan "...esclarecer, desplegar, compatibilizar, integrar y adaptar (cuando no reformular) a la Constitución". ${ }^{17}$; situaciones que, al decir del propio Sagüés, se pueden dar en varios casos:

- Cuando una norma constitucional permita variables interpretativas, en razón de las dudas que motiva su texto, en cuyo caso deberá optarse por una de ellas y aclarar el sentido de la norma;

- Cuando frente a una norma constitucional que no permite variables, en razón de su claridad, sea menester desarrollarla para comprender en su cobertura a aquellos casos que, en su detalle y concreción, pudieron haber escapado a lo que podría denominarse la previsión normativa del Legislador Constituyente;

- Cuando se está frente a redundancias o contradicciones, sea normativas o ideológicas, que obliguen a compatibilizar y, de no ser posible, optar;

- Cuando se tienen vacíos constitucionales (áreas no normadas), lo cual significará una labor de suplencia a través de los procedimiento de integración; y

- Cuando las nuevas realidades y entornos requieran y, más, exijan adaptar la norma constitucional para lograr una aplicación actualizada de la norma.

«...en síntesis, para el Tribunal Constitucional la interpretación constitucional rara vez será un trabajo de «descubrir» algo preexistente. Lo habitual consistirá en la «construcción» de 
respuestas constitucionales. Más que arqueólogo o explorador, el Tribunal será en aquella empresa artífice y autor.» ${ }^{18}$

\subsection{Interpretación previsora}

Esta es una interpretación en la que, atendiendo a los efectos que producirá la decisión proveniente de ella, realice un severo diagnóstico, calcule los resultados y tenga en cuenta sus efectos, los cuales serán generales, por lo que debe cuidarse que "...el producto interpretativo... ${ }^{19}$ sea provechoso y no dañino. En este punto conviene enfatizar la trascendencia de esta interpretación en un mundo en el cual la llamada globalización, sumada a los avances tecnológicos, sobre todo en los campos de la cibernética y las comunicaciones, imponen una dinámica distinta y ajena a la lógica tradicional que encierra la racionalidad del Legislador Constituyente. Por ello, dada esta dinámica, Sagüés acota:

«...Si el producto interpretativo es provechoso, corresponderá mantenerlo. En cambio, si ese producto es nocivo para un medio social, por más que sea generado por un procedimiento exegético impecable, habrá que desecharlo y retomar acto seguido el camino de la interpretación, en procura de un segundo resultado que sí sea positivo.

Tal es la metodología que propone la «interpretación previsora" del derecho, conveniente para cualquier rama del derecho, pero indispensable para un Tribunal Constitucional. A éste no puede legítimamente serle indiferente qué es lo que resuelve, so pretexto que cumpla su tarea si se limita a "aplicar» automática y asépticamente a la regla constitucional, como si ello consistiera en un teorema algebraico. Su papel de Poder del Estado, y de operador de una Constitución instrumento de Gobierno, le obliga a meritar cuidadosamente las secuelas de su pronunciamiento, máxime teniendo ellos efectos para todos. $\gg^{20}$ 


\subsection{Interpretación política}

Si la interpretación constitucional debe ser práctica, creativa y previsora, ello traduce su carácter político, porque ella no solo debe desarrollarse a través de un continuo y exigido ejercicio de definición, redefinición, efectivización y armonización de la Constitución, en orden a la custodia de su supremacía, sino que debe proteger y resguardar los principios, los valores y la doctrina que la sustenta; al punto que el mismo Sagüés enfatiza que:

«...en rigor de verdad, la supremacía ideológica de la Constitución es tal vez más trascendente que su supremacía normativa, ya que cada cláusula, precepto o inciso de dicha Constitución puede ser entendido de modo diferente según la clave ideológica que se maneje, circunstancias que destaca la importancia de la fidelidad al referido techo ideológico constitucional. $\gg^{21}$

Sin embargo, coincidiendo con el mismo autor, es menester aclarar que:

«Esa dimensión «política de la interpretación constitucional del Tribunal Constitucional ha sido aviesamente confundida por algunos con una «correspondencia» (de hecho, subordinación), que se dice "política», y que el Tribunal tendría que guardar hacia el partido gobernante o los titulares de los otros poderes.

Lo cierto es que el Tribunal no puede ignorar la realidad desde luego-; que debe auscultar las creencias sociales, y que no tiene por qué ser un órgano opositor nato del resto de las ramas del Poder. Pero su función principal, dentro del organigrama estatal, es la de operar como órgano de control constitucional de los demás centros de poder, oficiales y privados, ya que así lo quiso el pueblo al incorporarlo a la Constitución, y no oficiar como dependencia del partido victorioso en las urnas. ${ }^{22}$

\section{El Tribunal Constitucional peruano}

Siendo la interpretación constitucional consustancial al análisis de cons- 
titucionalidad, el ejercicio del control concentrado de constitucionalidad, dados sus efectos anulatorios erga omnes de la norma considerada inconstitucional y el nivel de aquella, sólo puede ser viable si su titular realiza una interpretación oponible con éxito a cualquier otra interpretación de la Constitución, provenga de quien provenga, lo cual no significa exclusividad interpretativa ${ }^{23}$. Por tanto, es inherente a la calidad de ente de control concentrado de constitucionalidad la de ser titular de la supremacía de la interpretación constitucional.

Desde este punto de vista, el carácter de intérprete supremo de la Constitución que corresponde al Tribunal Constitucional peruano, está dado por su propia naturaleza, de ser órgano de control concentrado de constitucionalidad de normas de rango superior; no por la mención expresa que pudiera haberse efectuado al respecto en la Constitución de 1993, que, como bien se sabe, omite calificarlo como tal.

Hubiera sido preferible que lo hiciera, como ocurre con las constituciones de otros países; pero, en todo caso, tal omisión, no es trascendente desde que, como está dicho, la calidad de intérprete supremo corresponde a la naturaleza de la función que cumple; no a que la Constitución u otra norma la mencione, expresamente o no.

Sin embargo, coincidiendo con Jorge Danó ${ }^{24}$ y Samuel Abad ${ }^{25}$, la omisión ha sido salvada, en cierta medida, si se tiene en cuenta que la Ley Orgánica del Tribunal Constitucional contiene tres normas que permiten concluir que en el plano normativo, y quizás aunque esa no fuera la intención del Legislador, se ha reconocido que el Tribunal Constitucional es el intérprete supremo de la Constitución. Tales normas son sus artículos 39 y 48 y su Primera Disposición General, que a la letra preceptúan:

Articulo $39^{\circ}$.- Los jueces deben aplicar una norma cuya constitucionalidad haya sido confirmada por el Tribunal.

Los jueces suspenden la tramitación de los procesos de acción popular sustentados en normas respecto de las cuales se ha planteado demanda de inconstitucionalidad ante el Tribunal, hasta que éste expida su resolución. ${ }^{26}$

23 Danós OrdoǸzz, Jorge. "Aspectos orgánicos del Tribunal Constitucional». En Lecturas sobre Temas Constitucionales. No. 10. Lima, Comisión Andina de Juristas. p. 285. $24 \quad$ Ibid., pp. 285-290.

25. Abal Yupanour, Samuel. "La jurisdicción constitucional en la Carta peruana de 1993: antecedentes, balances y perspectivas.”. En Lecturas Constitucionales Andinas. No. 4. Lima, Comisión Andina de Juristas y Fundación Konrad Adenauer. pp. 217-218.

26 Comisión Andina de Juristas. Op. cit., p. 81. 
Articulo $48^{\circ}$. - Si el conflicto versare sobre una competencia o atribución expresada en una norma con rango de ley, el Tribunal declara que la vía adecuada es la de acción de inconstitucionalidad.

Cuando se promueva un conflicto constitucional con motivo de una disposición, resolución o acto cuya impugnación estuviese pendiente ante cualquier juez o tribunal, éste suspenderá el procedimiento hasta la resolución del Tribunal Constitucional. ${ }^{27}$

«Primera.- Los jueces y Tribunales interpretan y aplican las leyes o toda norma con rango de ley y los reglamentos según los preceptos y principios constitucionales, conforme a la interpretación de los mismos que resulte de las resoluciones dictadas por el Tribunal Constitucional en todo tipo de procesos. $\nu^{28}$

El transcrito numeral 39, al preceptuar, por un lado, la obligación de los jueces de aplicar las normas declaradas constitucionales por el Tribunal Constitucional, y, por otro, la obligación de los jueces de suspender los procesos de acción popular que se sustenten en normas que estén siendo cuestionadas por causal de inconstitucionalidad ante el Tribunal Constitucional hasta que se expida la resolución final, está señalando la primacía de la interpretación constitucional que realiza dicho ente de control concentrado de constitucionalidad respecto de la que llevan a cabo los jueces, al ejercer el control difuso; al imponerles su obligatoria aplicación en el primer caso y la suspensión del proceso en el segundo, respectivamente.

El también transcrito numeral 48 , al preceptuar la obligación de los jueces de suspender los procedimientos motivados en impugnaciones de disposiciones, resoluciones o actos, que hayan dado lugar al planteamiento de un conflicto constitucional de competencia ante el Tribunal Constitucional, que éste esté conociendo, hasta que emita su respectivo pronunciamiento, está igualmente afirmando la primacía de la interpretación constitucional, que lleva a cabo aquel órgano de control concentrado de constitucionalidad; al imponerles la obligatoria suspensión del proceso de acción popular.

Por lo demás, la precitada Primera Disposición General, al ordenar la obligación de los jueces de interpretar y aplicar las leyes según los pre- 
ceptos y principios constitucionales, de acuerdo a la interpretación que de los mismos resulte de las resoluciones dictadas por el Tribunal Constitucional en los procesos en que interviene, está enfatizando, y con mayor claridad, la primacía de su interpretación, con el ingrediente adicional de que no sólo respecto de sus pronunciamientos en procesos de inconstitucionalidad (en los que se ejerce el control concentrado), sino de todos los procesos que conoce; sea cuando actúa como última instancia en los procesos de hábeas corpus, acción de amparo, acción de cumplimiento y hábeas data o cuando resuelve conflictos constitucionales de competencia o de atribuciones.

\section{Retos y riesgos}

Del rastreo realizado en lo que concierne al control de constitucionalidad en el Perú, desde los inicios de la República hasta la actualidad, se desprende que, a partir de la Constitución de 1979 se produce a nivel normativo constitucional un significativo avance, el cual, después de las pretendidas contramarchas producidas en el proceso de elaboración de la Carta de 1993, puede decirse que se reafirma, con algunos ajustes, con ciertas modificaciones y puntuales avances. No obstante, en la práctica, en la realidad concreta o en los hechos, tales avances normativo- constitucionales no marchan en paralelo, con lo cual el problema está en los operadores de tales normas, por una falta de conciencia de su trascendencia e importancia, dentro del sistema democrático y del Estado de Derecho.

En lo tocante al Tribunal Constitucional y, específicamente, a su rol de supremo intérprete de la constitucionalidad, queda claro que, correspondiéndole el control concentrado de constitucionalidad, tal calidad le es inherente y consustancial; independientemente de la omisión a aquella en que se incurre en el texto constitucional vigente y que los artículos 39 y 40, así como la Primera Disposición General de la Ley Orgánica del Tribunal Constitucional la hayan subsanado en cierta medida.

Es cierto que la normatividad específica que regula el funcionamiento del Tribunal Constitucional, básicamente la Ley No. 26435, a cuyo detalle no se ha dedicado esta investigación, por escapar a su propósito, presenta una limitación preocupante, cual es la exigencia de seis votos conformes, de un total de siete, para declarar la inconstitucionalidad de las normas objeto de cuestionamiento; por lo que, si se quiere que este ente de control concentrado de la constitucionalidad cumpla a cabalidad su rol, tendrán sus miembros que hacer importantes esfuerzos para con- 
cordar criterios y alcanzar la mayoría calificada que se exige o, en todo caso, tendrá que procurarse una reducción del número de votos conformes para la declaración de inconstitucionalidad.

En todo caso, es a los siete miembros del Tribunal Constitucional, recientemente elegidos por el Congreso de la República, a quienes compete una personal, directa y especialísima responsabilidad en la tarea de revaluar al Tribunal Constitucional peruano, para que cumpla a cabalidad su papel de supremo intérprete de la Constitución, ejerciendo un real control de la constitucionalidad; responsabilidad que debe comprometer al propio Estado y, en general, a toda la colectividad. Hay un desafio que vencer y, como afirma Nestor Sagüés, no todas son rosas en el jardín del Derecho Constitucional, por cuanto:

«Defender la "supremacía de la Constitución» puede ser una frase hueca si no se advierte que, en muchos momentos, el Tribunal Constitucional tendrá que privilegiar, de esa Constitución, algunos tramos sobre otros.

En concreto, el Tribunal deberá de vez en cuando hacer cohabitar y acomodar derechos entre sí, lo que puede implicar preferir algunos derechos sobre otros; o también, compatibilizar derechos personales con principios del sistema político.

No siempre, en efecto, le tocará al Tribunal Constitucional la grata tarea de explayar y aumentar el cupo de los derechos humanos, Eventualmente tendrá que poner coto a una gama de derechos, en resguardo de otro grupo de derechos. La libertad de contratar, por ejemplo, puede chocar con los derechos de gremios y de trabajadores, o la libertad de cátedra con los derechos de dirección de los propietarios de un establecimiento educativo privado. Paralelamente, el derecho al honor y a la privacidad puede no llevarse bien con el derecho de prensa a publicar sin censura previa, en donde está interesado, además del periódico del caso, el sistema democrático, a raíz del libre flujo de las ideas. El derecho a asociarse, a su turno, tiene que guardar correspondencia con la moral pública, reacia a admitir entidades que no respeten las pautas de ética colectiva.

La solución a estos encontronazos constitucionales demanda un espíritu particular, más de estadista que de otra cosa, entre quienes desempeñan la magistratura e integran un Tribunal o Corte especializada en el «fuero constitucional». Es cierto que hay aportes vitales en el derecho comparado, como la doctrina norteamericana de los «dos planos», o de las «libertades preferi- 
das», pero todavía habrá que proyectar a casos concretos tales pautas genéricas, que pueden alcanzar distintas gradaciones en cada comunidad nacional. ${ }^{29}$

Por ello, será necesario vencer los riesgos de la dependencia, la inoperancia y la incomprensión, entre otros, que se ciernen sobre el Tribunal Constitucional peruano, para convertirlo en un instrumento auténticamente cautelador de la constitucionalidad y, por lo tanto, de la institucionalidad democrática y del Estado de Derecho.

\section{Conclusiones}

1. Desde la fundación de la República ha existido una cierta preocupación por el control de la constitucionalidad de las normas, pero dentro de la línea adoptada por el Legislador Constituyente de la Carta de Cádiz de 1812 (línea Gaditana), que consideraba que era al Parlamento al que le competía tal tarea, en el marco de lo que podría denominarse un control político de constitucionalidad; hasta la Constitución de 1979, que eleva a categoría constitucional el control disperso de constitucionalidad e inaugura el control concentrado de constitucionalidad.

2. La constitucionalidad es un vínculo de armonía y concordancia plena entre la Constitución y las demás normas que conforman el sistema jurídico que aquella diseña; tanto en cuanto al fondo como a la forma. Es una suerte de cordón umbilical que conecta o une los postulados constitucionales con sus respectivos correlatos normativos, en sus diversos niveles de especificidad; $y$, por consiguiente, consustancial al proceso de implementación constitucional e imprescindible para la compatibilidad y la coherencia del sistema jurídico.

3. La interpretación constitucional es consustancial al análisis de constitucionalidad. Vale decir, le es inherente, forma parte de él; a tal punto que no puede haber análisis de constitucionalidad sin interpretación constitucional. Es más, tampoco puede haber constitucionalidad, conceptualmente hablando, sin interpretación constitucional, desde que aquella implica análisis y éste, a su vez, interpretación, que no es otra cosa que desentrañar el sentido de la Constitución, tanto como norma cuanto como conjunto normativo, estableciendo el parámetro de control 
y, a partir de ese punto, descubrir el sentido de cada uno de sus postulados, lo cual conlleva desentrañar su sentido axiológico, pero siempre por métodos jurídicos.

4. Interpretar es descubrir, en última instancia, el significado constitucionalmente adecuado, en base a una previa teoría de la Constitución, asentada en un concepto de Constitución democrática, que conlleve escudriñar el sentido de la norma constitucional, analizando los valores constitucionales de acuerdo a categorías jurídicas y no políticas, para lo cual es imprescindible contar con una adecuada técnica de interpretación constitucional.

5. La interpretación constitucional se peculiariza porque las normas constitucionales no son derivación ni desarrollo de otras superiores, que orienten y condicionen su aplicación, sino que tienen relación inmediata y directa con hechos políticos, históricos y culturales, determinantes de sus tendencias, contenidos y finalidades; de su modo de ser descriptivo $y$, a su vez, condicionante de todo el orden normativo del Estado.

6. La interpretación constitucional, además de integral, debe ser práctica, creativa, previsora y política; esto último referido a la protección y resguardo de los principios, los valores y la doctrina que sustentan la Constitución. Vale decir, el techo ideológico constitucional.

7. Siendo la interpretación constitucional consustancial al análisis de constitucionalidad, el ejercicio del control concentrado de constitucionalidad, dado sus efectos anulatorios erga omnes de la norma considerada inconstitucional y el nivel de aquella, sólo puede ser viable si su titular realiza una interpretación que pueda oponerse con éxito a cualquier otra interpretación de la Constitución, provenga de quien provenga, lo cual no significa exclusividad interpretativa.

8. Es inherente a la calidad de ente de control concentrado de constitucionalidad la de ser titular de la primacía de la interpretación constitucional.

9. El carácter de intérprete supremo de la Constitución que corresponde al Tribunal Constitucional peruano está dado por su naturaleza, de ser órgano de control concentrado de constitucionalidad de normas infraconstitucionales de primer rango; no por la mención expresa que pudiera haberse efectuado al respecto en la Constitución de 1993; que, como bien se sabe, omite calificarlo como tal.

10.Los artículos 39 y 48, así como la Primera Disposición General de la Ley Orgánica del Tribunal Constitucional, contienen normas que implican un reconocimiento a la calidad de intérprete supremo de la Constitución que posee el Tribunal Constitucional peruano.

11. El numeral 39 de la Ley Orgánica del Tribunal Constitucional al 
establecer, por un lado, la obligación de los jueces de aplicar las normas declaradas constitucionales por el Tribunal Constitucional, y, por otro, la obligación de los jueces de suspender los procesos de acción popular (que se sustenten en normas que estén siendo cuestionadas por causal de inconstitucionalidad ante el Tribunal Constitucional) hasta que se expida la resolución final, está señalando la primacía de la interpretación constitucional que realiza dicho ente de control concentrado de constitucionalidad respecto de la que llevan a cabo los jueces, al ejercer el control difuso; imponiéndoles su obligatoria aplicación en el primer caso y la suspensión del proceso en el segundo, respectivamente.

12.El artículo 48 de la Ley Orgánica del Tribunal Constitucional, al preceptuar la obligación de los jueces de suspender los procedimientos motivados en impugnaciones de disposiciones, resoluciones o actos, que hayan dado lugar al planteamiento de un conflicto constitucional de competencia ante el Tribunal Constitucional, que éste esté conociendo, hasta que emita su respectivo pronunciamiento, está igualmente afirmando la primacía de la interpretación constitucional, que lleva a cabo aquel órgano de control concentrado de constitucionalidad; al imponerles la obligatoria suspensión del proceso de acción popular.

13.La Primera Disposición General de la Ley Orgánica del Tribunal Constitucional, al normar que es obligación de los jueces interpretar y aplicar las leyes según los preceptos y principios constitucionales, de acuerdo a la interpretación que de los mismos resulte de las resoluciones dictadas por el Tribunal Constitucional en los procesos en que interviene, está enfatizando, y con mayor claridad, la primacía de su interpretación, con el ingrediente adicional que no sólo respecto de sus pronunciamientos en procesos de inconstitucionalidad (en los que se ejerce el control concentrado), sino de todos los procesos que conoce; sea cuando actúa como última instancia en los procesos de hábeas corpus, acción de amparo, acción de cumplimiento y hábeas data o cuando resuelve conflictos constitucionales de competencia o de atribuciones.

14. La normatividad específica que regula el funcionamiento del Tribunal Constitucional presenta una limitación preocupante, cual es la exigencia de seis votos conformes, de un total de siete, para declarar la inconstitucionalidad de las normas objeto de cuestionamiento; por lo que, si realmente se persigue que este ente de control concentrado de la constitucionalidad cumpla a cabalidad su rol, tendrán sus miembros que hacer importantes esfuerzos para concordar criterios y alcanzar la mayoría calificada que se exige o, en todo caso, tendrá que procurarse una reducción del número de votos conformes para la declaración de inconstitucionalidad. 


\section{Bibliografia}

AA. VV. «Doce ensayos sobre la nueva Constitución». Bogotá, Señal Edi1991 tora.

AA. VV. El Tribunal de Garantias Constitucionales en debate. Lima, 1986 Comisión Andina de Juristas y Consejo Latinoamericano de Derecho y Desarrollo.

AA VV: Sobre la jurisdicción constitucional, Lima, Pontificia Universidad 1990 Católica del Perú, Fondo Editorial, (coordinador Aníbal Quiroga León).

Abad Yupanqui, Samuel. «El valor de la jurisprudencia constitucional en 1995 el ordenamiento jurídico peruano». En Lecturas sobre Temas Constitucionales No. 11. Lima. Comisión Andina de Juristas.

Abad Yupanqui, Samuel. "Hábeas Data y conflicto entre organos consti-

1994 tucionales: dos nuevos procesos constitucionales». En Lecturas sobre Temas Constitucionales No. 10. Lima. Comisión Andina de Juristas.

Aguiar de Luque, Luis. "Alcances y límites de la justicia constitucio1993 nal». En el colectivo La jurisdicción constitucional. Costa Rica, Editorial Juricentro.

Aguirre Roca, Manuel. «El Tribunal de Garantías Constitucionales 1899 ante la crítica». En Revista Derecho. No. 42. Lima, Facultad de Derecho de la Pontificia Universidad Católica del Perú.

Alcalá-Zamora y Castillo, Niceto. Proceso. Autocomposición y 1947 autotutela. México. Imprenta Universitaria.

Allorio, Enrico. Problemas de Derecho procesal. Tomo I y II. Buenos 1963 Aires, Ediciones Jurídicas Europa-América.

Alsina, Hugo. Tratado teórico práctico de Derecho procesal civil y co1963 mercial. Tomo I. Buenos Aires, Ediar S.A. Editores.

Alvarez Simonetti, Manuel. «Debate en torno a la acción popular». 1973 En Revista Derecho. No. 32, Lima, PUC. 
Alzamora Valdez, Mario. Derecho Procesal Civil: teoría general del 1967 proceso. Lima. Tipográfica Peruana.

Alzamora Valdez, Mario. Derecho Procesal Civil. teoría general del $\mathrm{s} / \mathrm{n}$ proceso. 8va. Edición. Lima. Tipo Offset Sesator

Alzamora Valdez, Mario. La acción como derecho autónomo. En Re1951 vista del Foro. Año XXXVIII. No. 6. Lima.

Alzamora Valdez, Mario. Introducción a la ciencia del Derecho. Lima 1964 3ra. Edición.

Alzamora Valdez, Mario. Derecho Procesal Civil. Lima, Ediciones Pe1966 ruanas.

Aragón, Manuel, Solazabal, Juan José. Materiales de jurisprudencia 1994 constitucional. Madrid, Editorial Carpedi S.L.

Aragoneses, Pedro. Proceso y Derecho Procesal. Madrid, Editorial Aguila. 1960

Asamblea Constituyente (1978-1979). Actas del Pleno. Tomo V, Lima.

Asamblea Constituyente (1978-1979). Actas del Pleno. Tomo Vi, Lima.

Asamblea Constituyente (1978-1979). Actas del Pleno. Tomo Vil, Lima.

Asamblea Constituyente (1978-1979). Actas del Pleno. Tomo VIII, Lima.

Asamblea Constituyente (1978-1979). Diario de Debates de la Comi1985 sión Principal. Tomo I. Lima.

Asamblea Constituyente (1978-1979). Diario de Debates de la Comi1985 sión Principal. Tomo III. Lima.

Asamblea Constituyente (1978-1979). Diario de Debates de la Comisión Principal. Tomo IV. 
Ayasta Gonzales, Julio. «Inconstitucionalidad de las leyes», En: Revista 1945 de Jurisprudencia Peruana, año III, No. 16.

BARRAGÁn, Guillermo César. «Teoría normativa de la jurisdicción civil». 1987 En Revista Jurídica Argentina La Ley. tomo 1987-B. Argentina.

Barreto, Anselmo: La inconstitucionalidad de las leyes, Biblioteca de 1963 Cultura Peruana Contemporánea, Lima.

Bastida, Francisco J. Varela, Joaquín. Requejo, Juan Luis. Derecho 1992 Constitucional cuestionario comentado, I. Barcelona, Editorial Ariel, S.A..

Bazdresch, Luis. Garantias constitucionales. México, Editorial Trillas. 1987

Becerra, Gregorio. Análisis constitucional colombiano. Bogotá, Universi1986 dad Externado de Colombia.

Becerra Palomino, Carlos Enrique: Antecedentes sobre la jurisdicción 1991 constitucional en el Perú, En: Notarius, No. 2, año 2, año.

Benavides Correa, Alfonso. "Control Constitucional», En: Revista del 1979 Foro, Nos. 2, 3 y 4, Lima.

BIANCHI, Alberto. El control de constitucionalidad. El proceso y la juris1992 dicción constitucionales. Buenos Aires, Editorial Ábaco.

Bianchi, Alberto. "¿Está en crisis el sistema clásico de control de 1991 constitucionalidad?». En Revista Jurídica Argentina La Ley. Tomo 1990-E. Argentina.

Bidart Campos, Germán. El Derecho Constitucional del poder. Tomo I y 1967 II. Buenos Aires, Sociedad Anónima Editorial Comercial, Industrial y Financiera EDIAR.

Bidart Campos, Germán J. La Corte Suprema. Tribunal de Garantías 1984 Constitucionales. Buenos Aires. Ediar. 
Bidart Campos, Germán J. Derecho Constitucional 2 Tomos. Buenos 1964 Aires. Depalma.

Bidart Campos, Germán. «La jurisdicción constitucional». Ponencia al

1990 Segundo Congreso Nacional de Derecho Constitucional y Jornadas Internacionales de Derecho Constitucional, Lima, PUC.

Bidart Campos, Germán. Manual de Derecho Constitucional argentino.

1985 Buenos Aires, Sociedad Anónima Editorial Comercial, Industrial y Financiera EDIAR.

Biscaretti di RufFia, Paolo. Introducción al Derecho Constitucional com1975 parado. México, FCE.

Blancas Bustamante, Carlos; Landa Arroyo, César y Rubio Correa,

1992 Marcial. Derecho Constitucional General, Selección de lecturas de Derecho Constitucional. Lima, Fondo Editorial de la Pontificia Universidad Católica del Perú.

Blume Fortini, Ernesto. «El Tribunal de Garantías Constitucionales». 1983 En Revista Ius Et Praxis No. 3. Lima, Facultad de Derecho y Ciencias Políticas de la Universidad de Lima.

Blume Fortini, Ernesto. El control de la constitucionalidad (con especial 1996 referencia a Colombia y Perú). Lima, Editores Reunidos S.A.

Bolívar, Simón. «Discurso del Libertador al Congreso Constituyente de 1995 Bolivia». En Pensamiento Constitucional. Lima, Maestría en Derecho con mención en Derecho Constitucional y Fondo Editorial de la Pontificia Universidad Católica del Perú.

Borea Odría, Alberto. El Amparo y el Hábeas Corpus en el Perí de boy. 1985 Lima, Biblioteca Peruana de Derecho Constitucional.

Borea Odría, Alberto. Evolución de las Garantias Constitucionales. 1996 Lima, Grijley E.I.R.L.

BozA, Edilberto: «Inconstitucionalidad de la ley», En: Revista del Foro, 1931 Lima. 
Bustamante Belaunde, Alberto. «El Tribunal de Garantías Constitucio1981 nales: un proyecto de ley que no ofrece garantías». En Revista Quehacer. No. 10. Lima, Desco.

Bustamante Belaunde, Alberto. "La irretroactividad de los fallos del 1982 Tribunal de Garantías Constitucionales». En Revista Derecho. No. 36, Lima, PUC.

Calamandrei, Piero. Estudios sobre el Proceso Civil. Buenos Aires, Bi1961 bliográfica Argentina.

Calamandrei, Piero. Instituciones del Proceso Civil. Buenos Aires, 1943 Depalma.

Cano Mata, Antonio. Comentarios a la Ley Orgánica del Tribunal 1986 Constitucional. Madrid, Editorial Revista de Derecho Privado.

Cámara de Dirutados. Actas Oficiales y extractos de las sesiones en que 1910 fue discutida la Constitución de 1860». Convención Nacional 1855-1856. Lima, Empresa Tipográfica Unión.

Cappelletti, Mauro. Proceso. Ideologias y sociedad. Buenos Aires. Ejea. 1979

Cárdenas Quirós, Carlos. «El Tribunal de Garantías Constitucionales y 1981 la Constitución del Perú de 1979». En Revista del Foro. No. 2, Lima, Colegio de Abogados de Lima.

Carnelutti, Francisco. Instituciones del Proceso Civil. Buenos Aires, Edi1973 ciones Jurídicas Europa-América.

Carnelutti, Francisco. Sistemas de Derecho Procesal Civil. Buenos Aires, 1944 UTEHA.

Carnelutti, Francisco. Derecho Procesal Civil y Penal. Tomo I. Buenos 1971 Aires, Ediciones Jurídicas Europa-América.

Carpio Marcos, Edgard E. «Derecho Procesal Constitucional y juris1992 dicción constitucional». En Revista El Jurista. Año II, No. 6. Lima. 
Carrón Lugo, Jorge. "Jurisprudencia del Tribunal de Garantías Cons1985 titucionales. Comentarios». En Revista del Foro. Lima.

Casós, Fernando: Proyecto de Reforma de la Constitución de 1856, conser1858 vando noventisiete disposiciones constitucionales, suprimiendo, modificando o derogando los demás articulos, y aumentando otros nuevos, Lima, A. Alfaro.

Cea Egaña, José Luis. "Tratado de la Constitución de 1980. Característi1988 cas generales garantías Constitucionales». Santiago de Chile, Editorial Jurídica de Chile.

Claria Olmedo, Jorge. Derecho Procesal. Tomo I y II Buenos Aires, 1982 Depalma.

Colegio de Abogados de Lima. «Pronunciamiento del Colegio de Abo1987 gados de Lima sobre la Acción de Inconstitucionalidad (artículo 298, inciso 1). En Revista del Foro. No. 1, Lima.

Colomer Viadel, Antonio. Introducción al constitucionalismo iberoame1990 ricano, Madrid, ICI.

Colomer Viadel, Antonio. "Rasgos del constitucionalismo iberoameri1991 cano». En _Revista Ius Et Praxis No. 17. Lima, Facultad de Derecho y Ciencias Políticas de la Universidad de Lima, Centro de Investigación Jurídica.

Comisión Andina de JuRISTAS. "Garantias Constitucionales legislación 1996 pigente». Lima, Comisión Andina de Juristas.

Comisión Andina de Juristas. «Del golpe de Estado a la Nueva Cons1993 titución». En Lecturas Sobre Temas Constitucionales No. 9. Lima, Comisión Andina de Juristas.

Comisión Andina de Juristas. "Jurisprudencia, Caso Marbury Vs. 1988 Madison». En Lecturas sobre Temas Constitucionales No. 2. Lima, Comisión Andina de Juristas.

Comisión Reformadora del Código Civil (1923). Actas de las Sesiones. 1928 Tomo I. Segunda Edición. Lima. Imprenta C.A. Castrillón. 
Comisión Reformadora del Código Civil (1923). Actas de las Sesiones. 1928 Tomo VIII. Segunda Edición. Lima. Imprenta C.A. Castrilló.

Congreso: Diario de Debates del Congreso reunido en 1860, que ba re1860 formado la Constitución dada por la Convención en 1856. Lima, Tipográfica del Comercio, 1860.

Congreso Constituyente de 1931. Diario de los Debates. Tomo III. 1936 Lima, Empresa Editora La Nacional.

Congreso Constituyente de 1931. Diario de los Debates. Tomo VI. 1936 Lima, Empresa Editora La Nacional.

Congreso Constituyente de 1931. Diario de los Debates. Tomo VIII. 1936 Lima, Empresa Editora La Nacional.

Convención Nacional 1855 - 1856. Actas oficiales y extractos de las se1910 siones en que fue discutida la Constitución de 1860. Publicación ordenada por la Cámara de Diputados. Lima, Empresa Tipográfica La Unión.

Conso Masías, Alfredo. El Tribunal de Garantías Constitucionales. 1984 Prontuario. Arequipa, Edigrap Editores.

Cortez Dominguez, Valentín. Derecho Procesal Civil. Valencia, Tirant 1995 lo Blanch.

Couture, Eduardo. Estudios de Derecho Procesal Civil. Tomo I. Bue1979 nos Aires. Ediciones Depalma.

Couture, Eduardo. Fundamentos del Derecho Procesal Civil. Buenos 1993 Aires, Editorial Depalma.

Couture, Eduardo J. Fundamentos del Derecho Procesal Civil. 3a. Edi1985 ción Póstuma. Buenos Aires. Depalma.

Cruz Villalón, Pedro. La formación del Sistema Europeo de control de 1987 constitucionalidad (1918-1939). Madrid, Centro de Estudios Constitucionales. 
Cumplido Cereceda, Francisco; Nogueira Alcalá, Humberto. Teoría de

1985 la Constitución. Santiago de Chile, Fondo de Cultura Económica.

Chichizola, Mario I. «El Debido Proceso como Garantía Constitucio1983 nal». En Revista Juridica Argentina La Ley. Tomo 1983-C. Argentina.

Chirinos Soto, Enrique. Constitución de 1993: lectura y comentario. 1995 Lima, Empresa Editora Piedul S.R.L.

Chirinos Soto, Enrique. Cuestiones constitucionales 1933-1990. Lima, 1991 Fundación M. J. Bustamante De la Fuente.

Danós Ordoñez, Jorge. "Aspectos orgánicos del Tribunal Constitucio1994 nal». En Lecturas sobre Temas Constitucionales. No. 10. Lima, Comisión Andina de Juristas.

Danós OrdoñEz, Jorge; Sousa Calle, Martha. «El control jurisdiccional 1987 de la constitucionalidad de las normas jurídicas de carácter general». En La Constitución Peruana de 1979 y sus problemas de aplicación. Lima, Cultural Cuzco S.A.

Danós Ordoñez, Jorge; Sousa Calle, Martha. «El control jurisdiccional 1988 de la constitucionalidad de las normas jurídicas de carácter general». En Lecturas sobre Temas Constitucionales. Lima, Comisión Andina de Juristas.

Danós OrdoñEz, Jorge. «La garantía constitucional de la acción popu1990 lar». En Lecturas sobre Temas Constitucionales. No. 04. Lima, Comisión Andina de Juristas.

De Bernardis Llosa, Luis Marcelo. La garantía procesal del Debido 1995 Proceso. Biblioteca Universitaria de Derecho Procesal Civil. Lima.

De la RúA, Fernando. Proceso y justicia (temas procesales). Buenos Aires, 1980 Lerner Editores Asociados.

De OtTo, Ignacio. Derecho Constitucional sistema de fuentes. Barcelo1991 na, Editorial Ariel, S.A. 
Dermizaky Peredo, Pablo. Derecho Constitucional. Cochabamba, Edito1991 rial Arol.

De Santo, Víctor. Tratado de los Recursos. Tomo I. Buenos Aires, Edi1987 torial Universidad.

Devis Echandía, Hernando: Compendio de Derecho Procesal, Tomo I, 1976 Teoría General del Proceso. Bogotá, Editorial ABC.

De Vergottini, Giuseppe. Derecho Constitucional comparado. Madrid, 1983 Espaza-Calpe.

De Vergottini, Giuseppe: «Sobre la efectividad del control jurisdiccio1984 nal en el ordenamiento iberoamericano", En: Revista Ius Et Praxis No. 4, Universidad de Lima.

Devis Echandía, Hernando. «El Derecho de Contradicción». En Re1994 vista Gaceta Juridica, Tomo IV. Lima.

Documentos. «IV Congreso Nacional de Derecho Constitucional». En 1994 Pensamiento Constitucional. Lima, Maestría en Derecho con mención en Derecho Constitucional de la Pontificia Universidad Católica del Perú, Fondo Editorial.

Duverger, Maurice. «Instituciones Politicas y Derecho Constitucional》. 1984 Barcelona, Ariel.

Dugo, Sergio O.; Lugones, Narciso. «El Recurso extraordinario fede1991 ral entre la Constitución y la Ley». En Revista Juridica Argentina La Ley. Tomo 1990-E. Argentina.

Echandia, Devis. Teoria general del Proceso. Tomo I. Buenos Aires, 1984 Editorial Universidad.

Echave, Víctor Manuel: «Inconstitucionalidad de las leyes», En: Revista 1963 Jurídica del Perú, No. 1, año XIV, Lima.

Echecopar García, Luis. "Prólogo». En Anteproyecto de Constitución 1962 de 1931 de la Comisión Manuel Vicente Villarán. Lima, P.C. Villanueva. 
Eguiguren, Luis Antonio: La inconstitucionalidad de las leyes Lima, Im1945 prenta Torres Aguirre S.A.

Eguiguren Praeli, Francisco: «Normas contrarias a la Constitución o a 1984 la Ley», En: Revista del Foro, No. 1, año LXXI.

Eguiguren Praeli, Francisco: La Constitución Politica de 1979 y sus pro1987 blemas de aplicación. Lima, Cultural Cuzco S.A.

Eguiguren Praeli, Francisco. «El Tribunal de Garantías Constituciona1991 les: las limitaciones del modelo y las decepciones de la realidad». En Lecturas Constitucionales Andinas». No. 7. Lima, Comisión Andina de Juristas.

Eguiguren Praeli, Francisco. Los retos de una democracia insuficiente. 1990 Lima, Comisión Andina de Juristas y Fundación Friedrich Naumann.

Escobar Fornos, Iván. «El Amparo». En Monografías Juridicas, Bogo1990 tá.

Eто CRuz, Gerardo. «Introducción bibliográfica a los derechos y garan1990 tías constitucionales». En Lecturas sobre Temas Constitucionales. No. 05. Lima, Comisión Andina de Juristas.

Eto Cruz, Gerardo. «Breve introducción al Derecho Procesal Constitu1992 cional: notas para un estudio de la jurisdicción constitucional en el Perú", Trujillo, Revista Jurídica del Colegio de Abogados de La Libertad, No. 129, segunda edición.

Fairen Guillén, Víctor. Doctrina general del Derecho Procesal. Hacia 1990 una teoria y ley Procesal General. Barcelona. Bosch.

Fernández Segado, Francisco. «El Modelo Francés de control político 1990 de la constitucionalidad de las leyes: su evolución». En el colectivo Sobre la jurisdicción constitucional. Lima, Fondo Editorial de la Pontificia Universidad Católica del Perú.

Fernández Segado, Francisco. Seminario jurisdicción constitucional. Lima, versión magnetofónica de conferencia dictada el 13.06.96. 
Ferrero Rebagliati, Raúl. «Teoria del Estado. Derecho Constitucional». 1966 Lima, Ediciones Librería Studium S.A.

Ferrero, Augusto. «Derecho Procesal Civil-Excepciones». Lima. Edi1980 torial Ausonia.

Ferrero Rebaglati, Raúl: «El liberalismo peruano y la Constitución de 1956 1856», Revista del Foro, Lima, año XLIII, No. 3, SetiembreDiciembre.

Ferrero Rebagliati, Raúl: «El ontrol de constitucionalidad de las leyes»; 1960 Revista Jurídica del Perú, No. 3, año XI.

Figueroa, Luis Mauricio. La Constitución inglesa. México, Editorial 1991 Jus.

Fix Zamudio, Héctor. "La justicia constitucional en América Latina».

1991 En Lecturas Constitucionales Andinas. No. 1. Lima, Comisión Andina de Juristas.

Fix Zamudio, Héctor. «Breves reflexiones sobre la interpretación consti-

1993 tucional». En el colectivo La jurisdicción constitucional. Costa Rica, Editorial Juricentro.

Fix Zamudro, Héctor. «Los tribunales constitucionales en 1982 Latinoamérica». En Revista Jurídica del Perú. No. l, Lima.

Fix Zamudio, Héctor. Veinticinco años de evolución de la justicia consti1968 tucional (1940 - 1965). México, Universidad Nacional Autónoma de México.

Furnish, Dale B. "La 'Revisión judicial' de la constitucionalidad de las 1990 leyes en los Estados Unidos». En el colectivo Sobre la jurisdicción constitucional. Lima, Fondo Editorial de la Pontificia Universidad Católica del Perú.

Gálvez, José: La Convención Nacional y la Constitución de 1856. Lima, 1858 Imprenta de José Félix Moreno.

Garcés Peralta, Carolina. «Chile: leyes interpretativas e interpretación 1993 de la Constitución: A propósito de una sentencia del Tribunal 
Constitucional». En Lecturas Constitucionales Andinas No. 2. Lima, Comisión Andina de Juristas.

García Belaunde, Domingo: "Control constitucional», En: Revista del 1979 Foro, Nos. 2, 3 y 4, Lima.

García Belaunde, Domingo. "La acción de inconstitucionalidad en el 1991 Derecho comparado". En Lecturas Constitucionales Andinas No. 1. Lima, Comisión Andina de Juristas.

García Belaunde, Domingo. "Procesos constitucionales en la Constitu1990 ción brasileña de 1988». En Lecturas sobre Temas Constitucionales. No. 5. Lima, Comisión Andina de Juristas.

Garcia Belaunde, Domingo. «La interpretación constitucional como 1994 problema». En Pensamiento Constitucional. Lima, Maestría en Derecho con mención en Derecho Constitucional de la Pontificia Universidad Católica del Perú, Fondo Editorial.

García Belaunde, Domingo. «La jurisdicción constitucional en el 1978 Perú». En Revista de la Universidad Católica. (nueva serie). No. 3. Lima.

García Belaunde, Domingo. «La jurisdicción constitucional en el 1988 Perú». En Revista de Derecho, Universidad Central de Chile.

García Belaunde, Domingo. «Procesos constitucionales en América La1996 tina». En Desafíos Constitucionales Contemporáneos. César Landa y Julio Faúndez (Editores). Lima, Maestría en Derecho con mención en Derecho Constitucional de la Pontificia Universidad Católica del Perú, School of Law University of Warwick y Fondo Editorial de la Pontificia Universidad Católica del Perú.

García Belaunde, Domingo. «Procesos constitucionales en la Constitu1990 ción brasileña de 1988». En Lecturas sobre Temas Constitucionales. No. 5. Lima, Comisión Andina de Juristas.

García Belaunde, Domingo. «La nueva Constitución del Perú: Poder 1996 Judicial y Garantías Constitucionales». En Desafìos Constitucionales Contemporáneos. César Landa y Julio Faúndez (Editores). 
Lima, Maestría en Derecho con mención en Derecho Constitucional de la Pontificia Universidad Católica del Perú, School of Law University of Warwick y Fondo Editorial de la Pontificia Universidad Católica del Perú.

García Belaunde, Domingo: "Control de la constitucionalidad de las 1989 leyes en el Perú». En Revista Ius Et Praxis. No. 13, Lima, Universidad de Lima.

García Belaunde, Domingo. Constitución y política. Lima, Editorial y 1991 Distribuidora de Libros S.A.

García Belaunde, Domingo. El hábeas corpus en el Perú. Lima, Univer1979 sidad Nacional Mayor de San Marcos.

García Belaunde, Domingo. Esquema de la Constitución peruana. 1992 Lima, Ediciones Justo Valenzuela E.I.R.L.

García Belaunde, Domingo. «El constitucionalismo peruano en la pre1989- sente centuria». En Revista Derecho. Nos. 43-44. Lima, Fa1990 cultad de Derecho de la Pontificia Universidad Católica del Perú.

García Belaunde, Domingo; Fernández Segado, Francisco. "La Consti1994 tución peruana de 1993". Lima, Editora Jurídica Grijley.

García Belaunde, Domingo, con la colaboración de Gutiérrez Camacho. 1993 Walter. "Las constituciones del Perí». Lima, Edición Oficial.

García Belaunde, Domingo. «Garantías Constitucionales en la Consti1994 tución peruana de 1993». En Lecturas sobre Temas Constitucionales No. 10. Lima, Comisión Andina de Juristas.

García Belaunde, Domingo. "La influencia española en la Constitu1982 ción peruana (a propósito del Tribunal de Garantías Constitucionales)". En Revista de Derecho Político. No. 16, Madrid, (III).

García Belaunde, Domingo; Fernández Segado, Francisco; Hernández 1992 Valle, Rubén. Coordinadores en el colectivo "Los sistemas constitucionales iberoamericanos. Madrid, Editorial Dykinson. 
García Belaunde, Domingo. «Sobre la Jurisdicción Constitucional» 1990 (texto preparado especialmente para la Enciclopedia Jurídica Omeba). En el colectivo Sobre la jurisdicción constitucional. Lima, Fondo Editorial de la Pontificia Universidad Católica del Perú.

García Belaunde, Domingo. "Teoría y práctica de la Constitución». 1989 Tomo I. y II Lima, Editorial y Distribuidora de Libros S.A.

García Belsunce, Horacio. Garantias Constitucionales. Buenos Aires, 1984 Ediciones Depalma, 1984.

García de EnTerría, Eduardo. La Constitución como norma y el Tribu1985 nal Constitucional. Madrid, Editorial Civitas.

García Laguardia, Jorge Mario. «Justicia constitucional, hábeas corpus 1993 y debido proceso». En el colectivo La jurisdicción constitucional. Costa Rica, Editorial Juricentro.

García Martínez, María Asunción. El recurso de inconstitucionalidad. 1992 El proceso directo de inconstitucionalidad. Madrid, Editorial Trivium, S.A.

Gaona Cruz, Manuel. Control y reforma de la Constitución en Colombia. 1988 Bogotá, Ministerio de Justicia, 1988.

Gimeno Sendra, Vicente; Garberi Llobregat, José. Los procesos de amparo 1994 (ordinario, constitucional e internacional). Madrid, Editorial Colex.

Goldschmidt, James. Derecho Procesal Cipil. Barcelona. Editorial La1936 bor.

Gómez Mendoza, Gonzalo. Garantias de protección de la persona. 1996 Lima, Editorial Rodas.

González Alvarez, Daniel. "Justicia Constitucional y Debido Proceso». 1993 En el colectivo La jurisdicción constitucional. Costa Rica, Editorial Juricentro.

Gonzáles Casanova, José Antonio. Teoría del Estado y Derecho Constitu1991 cional. Barcelona, Ediciones Vicens-Vives, S.A. 
Gozaini, Osvaldo Alfredo. Introducción al nuevo Derecho Procesal. 1988 Buenos Aires. Ediar.

Gros Espiell, Héctor. "El Derecho Internacional en la jurisdicción». 1993 En el colectivo La jurisdicción constitucional». Costa Rica, Editorial Juricentro.

Guasp Delgado, Jaime. La pretensión procesal. Madrid. Editorial 1981 Civitas S.A.

Gutiérrez, Carlos José. «Evolución de la justicia constitucional en Cos1993 ta Rica». En el colectivo La jurisdicción constitucional. Costa Rica, Editorial Juricentro.

Falcón, Enrique. Gráfica Procesal. Buenos Aires, Editorial Abelardo 1987 Perrot.

Haurou, André. Derecho Constitucional e instituciones políticas. Barcelo1980 na, Editorial Ariel.

Henao Hidrón, Javier. Panorama del Derecho Constitucional colombia1992 no. Bogotá, Temis.

Hernández Valle, Rubén. "La tipología de las sentencias constituciona1993 les con efectos fiscales». En el colectivo La jurisdicción constitucional. Costa Rica, Editorial Juricentro.

Hernández Valle, Rubén. «Legitimación democrática de los tribunales 1993 constitucionales». En el colectivo La jurisdicción constitucional. Costa Rica, Editorial Juricentro.

Heredia Mendoza, Madeleine. Naturaleza procesal de la acción de am1995 paro. Lima, Editorial Cuzco S.A.

Historia Constitucional. "Discurso con que la Comisión de Constitu1994 ción presentó el Proyecto de Ella al Congreso Constituyente». En Pensamiento Constitucional. Lima, Maestría en Derecho con mención en Derecho Constitucional de la Pontificia Universidad Católica del Perú, Fondo Editorial. 
Hitters, Juan Carlos. "Derecho Procesal Constitucional». En Revista 1993 Ius Et Praxis, No. 21-22. Lima.

Hoyos Henrechson, Francisco. Temas fundamentales de Derecho Proce1987 sal. Santiago de Chile. Editorial Jurídica de Chile.

Instituto de InVestigaciones JuRIdicas. Garantias jurisdiccionales para 1982 la defensa de los derechos humanos en iberoamérica». México, UNAM.

Instituto Interamerucano de Derechos Humanos. Agenda para la con1990 solidación de la democracia. San José.

Itzighsohn de Fischaman, María. Voz «Recurso en el Proceso Civil». 1977 En Enciclopedia Jurídica Omeba. Tomo XIV. Buenos Aires. Driskill S.A.

Jimenez de PARGA, Manuel. Los regimenes políticos contempóraneos. Ma1983 drid, Tecnos.

Karlan, Marcos. La formación del Estado nacional en América Latina. Santiago de Chile, Editorial Universitaria.

Kelsen, Hans. Que es Justicia. Barcelona, Editorial Ariel, S.A.. 1992

Kelsen, Hans. Teoría Pura del Derecho. Sétima Edición. México, Edito1993 rial Porrúa.

Landa Arroyo, César. «Del Tribunal de Garantías al Tribunal Constitu1995 cional: el caso peruano. En Pensamiento Constitucional. Lima, Maestría en Derecho con mención en Derecho Constitucional y Fondo Editorial de la Pontificia Universidad Católica del Perú.

Landa Arroyo, César. «La vigencia de la Constitución en América Lati1996 na”. En Desafios Constitucionales Contemporáneos. César Landa y Julio Faúndez (Editores). Lima, Maestría en Derecho con mención en Derecho Constitucional de la Pontificia Universidad Católica del Perú, School of Law University of Warwick y Fondo Editorial de la Pontificia Universidad Católica del Perú. 
Landa Arroyo, César. "Apuntes para una teoría democrática en Améri1994 ca Latina». Lima, Maestría en Derecho con mención en Derecho Constitucional y Fondo Editorial de la Pontificia Universidad Católica del Perú.

Landa Arroyo, César; García Belaunde, Domingo; y Rubio Correa, 1994 Marcial (editores). Pensamiento Constitucional. Lima, Maestría en Derecho con mención en Derecho Constitucional y Fondo Editorial de la Pontificia Universidad Católica del Perú.

Lassalle, Ferdinand. ¿Qué es una Constitución? Estudio Preliminar de 1989 Elíseo Aja. Barcelona, Editorial Ariel, S.A.

Lazarini, José Luis. El Juicio de Amparo. Buenos Aires, La Ley. 1967

León Barandiarán, José. «El Tribunal de Control de la Constitucio1969 nalidad y de la Legalidad». En_Revista del Foro. No. 1, Lima, Colegio de Abogados de Lima.

Liebman, Enrico Tulio. Manual de Derecho Procesal Civil. Buenos Aires, 1980 Ediciones Jurídicas Europa-América.

Linares A.M., José Octavio. Derecho Procesal Civil. Vol. II, Lima, 1984 Editorial Sudamericana S.A.

Loewenstein, Karl. Teoria de la Constitución. Barcelona, Editorial Ariel. 1982

Lucas Verdú, Pablo: Curso de Derecho Politico. Madrid, Editorial 1984 Tecnos S.A.

Moderne, Franck. "El Control previo de constitucionalidad en la Euro1993 pa contemporánea». En el colectivo La jurisdicción constitucional. Costa Rica, Editorial Juricentro.

Monroy Gálvez, Juan. Temas de Proceso Cipil. Lima, Edición Librería 1987 Studium.

Monroy Gálvez, Juan. "Conceptos elementales de Proceso Civil (I)». En Diario oficial El Peruano. Cuerpo B. Derecho \& Economía. Lima Edición del 24.06.92. 
Monroy Gálvez, Juan y Quiroga León, Aníbal. Las excepciones en el

1982 Proceso Civil Peruano. Tesis para optar el grado de Bachiller en Derecho. Facultad de Derecho Pontificia Universidad Católica del Perú.

Montero Aroca, Juan, Ortells Ramos, Manuel; Gómez Colomer, Juan

1989 Luis; Monton Redondo, Alberto. Derecho Jurisdiccional. Barcelona. Bosch. 2 Tomos.

Morello, Augusto. «La Acción, la Justicia y el Proceso». En Libro 1971 Homenaje a Amilcar A. Mercader: Problemática del Derecho Pocesal. La Plata, Editora Platense.

Muñoz Quesada, Hugo Alfonso. "La Sala Constitucional como poder 1993 político». En el colectivo "La jurisdicción constitucional». Costa Rica, Editorial Juricentro.

Murillo de la Cueva, Pablo Lucas: «El examen de constitucionalidad 1989 de las leyes y la soberanía parlamentaria», En: Ius Et Praxis, No. 14, Universidad de Lima.

Nogueira Alcalá, Humberto. «La jurisdicción constitucional como ex1990 presión del Derecho Comparado». Ponencia al Segundo Congreso de Derecho Constitucional, Lima.

Nogueira Alcalá, Humberto. «Consideraciones sobre la jurisdicción, 1991 constitucionalidad y la acción de inconstitucionalidad en el Derecho Comparado». En Lecturas Constitucionales Andinas. No. l. Lima, Comisión Andina de Juristas.

OrTeCHO VILLENA, Víctor Julio. Jurisdicción constitucional, procesos cons1994 titucionales, hábeas corpus y acción de amparo, hábeas data y acción de cumplimiento, acción popular e inconstitucionalidad". Trujillo, Fondo Editorial de la Universidad Antenor Orrego de Trujillo.

Ortecho Villena, Víctor Julio. Derechos y garantias constitucionales: 1985 hábeas corpus, acción de amparo, acción popular, inconstitucionalidad. Trujillo, Marsol Perú Editores S.A.

Páez Velandia, Didimo. El control de la constitucionalidad en los estados 
1985 latinoamericanos y fundamentalmente en la República de Colombia. Bogotá, Editorial de la Revista «Derecho Colombiano».

Palomino Manchego, José. «Notas sobre el Tribunal de Garantías 1982 Constitucionales». En Revista Juris. No. 1, Lima, UNMSM.

Palomino Manchego, José. El Tribunal de Garantías Constitucionales. 1983 Lima, UNMSM.

Pareja Paz Soldán, José. Derecho Constitucional peruano y la Constitu1980 ción de 1979. Tomo II. Lima, Editora Ital Perú S.A.

Paromi Renón, Carlos: «La defensa de la legalidad en la Constitución de 1988 1979», En: Vox Lucis, No. 2, año I, Universidad Nacional Mayor de San Marco, Lima 1988.

Peláez BAzÁn, Mario. El Tribunal de Garantias Constitucionales y un 1980 anteproyecto de su Ley Orgánica. Lima, Editorial Vicente Solsol.

Peláez Bazán, Mario. Hacia la justicia constitucional. Lima, Editorial 1984 Andina.

Pecchi Croce, Carlos. «Constitución Política y Proceso Civil». En Re1985 vista de Derecho de la Universidad de Concepción. Año LII, No. 178. Chile.

Peyrano, Jorge Walter. Procedimiento Civil y Comercial. Tomo I. Ro1991 sario, Editorial Juris.

Pibernat Domenech, Javier. Prácticas de Derecho Constitucional. Bar1988 celona, Editorial Ariel S.A.

Piza E., Rodolfo. «Justicia Constitucional y Derecho de la Constitu1993 ción». En el colectivo La jurisdicción constitucional. Costa Rica, Editorial Juricentro.

Power Manchego-Muñoz, Jorge. Constitución y justicia. Lima. Edi1984 torial Andina. 
Quiroga Lavie, Humberto. Curso de Derecho Constitucional. Buenos Ai1985 res, Ediciones Depalma.

Quiroga Lavie, Humberto. Derecho Constitucional. Buenos Aires, Co1978 operadora de Derecho y Ciencias Sociales.

Quiroga León, Aníbal. «El sistema de justicia constitucional en el 1988 Perú». En Lecturas sobre Temas Constitucionales. No. 2. Lima, Comisión Andina de Juristas.

Quiroga León, Aníbal. "Las garantías constitucionales de la administra1989 ción de justicia». En La Constitución diez años después. Lima. Fundación Frederic Naumann y Derecho y Sociedad.

Quiroga León, Aníbal. «Los Derechos Humanos. El debido proceso y 1987 las garantías constitucionales de administración de justicia». En La Constitución peruana de 1979 y sus problemas de aplicación. Once estudios interpretativos. Francisco Eguiguren. Director. Lima. Cultural Cuzco.

Quiroga León, Aníbal. "Conceptos básicos en el estudio del Derecho 1986 Procesal: a propósito de la ciencia del proceso. En Revista Derecho. No. 40. Lima. Pontificia Universidad Católica del Perú.

Quiroga León, Aníbal. Una aproximación a la justicia constitucional: el 1990 modelo peruano. Lima, Fondo Editorial de la Pontifica Universidad Católica del Perú.

Quispe Correa, Alfredo. «Amparo contra normas y control difuso». En 1996 Autos y Vistos Comentarios Jurisprudenciales. Comisión Especial de Análisis y Crítica de las Resoluciones y Sentencias Judiciales del Colegio de Abogados de Lima. Lima, Gaceta Jurídica Editores S.C.R.L.

Redenti, Enrico. Derecho Procesal Civil Tomo I. Buenos Aires. Edi1957 ciones Jurídicas Europa-América.

Restrepo Piedrahita, Carlos. «Tres rutas históricas hacia la constitución 1994 colombiana de 1991». En Problemas Actuales del Derecho Constitucional, Estudios de Homenaje a Jorge Carpizo. México, Universidad Autónoma de México. 
Rocco, Ugo. Tratado de Derecho Procesal Civil. Volumen I. Bogotá1969 Buenos Aires. Temis-Depalma.

Rocco, Ugo. Tratado de Derecho Procesal Civil. Buenos Aires. 1978 Depalma.

Rodríguez Brignardello, J. Hugo. «Perú: El fallo en la acción de 1993 inconstitucionalidad contra el Decreto Legislativo No. 650 sobre compensación por tiempo de servicio». En Lecturas Constitucionales Andinas No. 02. Lima, Comisión Andina de Juristas.

Rodríguez Domínguez, Elvito: «Derecho Procesal Constitucional pe1991 ruano». En Notarius Revista del Colegio de Notarios de Lima. Año II. No. 2, Lima.

RosatTI, Horacio. El derecho a la jurisdicción antes del proceso. Buenos 1984 Aires, Depalma.

Rubio Correa, Marcial. Para conocer la Constitución de 1993. Lima, 1996 Desco, Sexta Edición.

SÁCHICA, Luis Carlos. Constitucionalismo colombiano. Bogotá, Temis. 1991

SÁCHICA, Luis Carlos. El Control de constitucionalidad. Bogotá, Editorial 1988 Temis S.A.

SÁcHICA, Luis Carlos. El nuevo constitucionalismo colombiano. Bogotá, 1993 Temis.

Sáchica, Luis Carlos; y Perdomo, Jaime Vidal. La Constituyente de 1991 1991. Bogotá, Cámara de Comercio de Bogotá.

SAGǗés, Néstor Pedro. «Derecho Procesal Constitucional y jurisdicción 1981 constitucional». En Revista Jurídica Argentina La Ley. Tomo 1981-C. Argentina.

SAGÜÉs, Néstor Pedro. Recurso Extraordinario. Tomos I y II. Buenos 1984 Aires, Ediciones Depalma. 
SAGÜÉs, Néstor Pedro. «La interpretación constitucional». Ponencia al 1990 Segundo Congreso Nacional y Jornadas Internacionales de Derecho Constitucional. Lima. PUC.

SAGÜÉs, Néstor Pedro. "Tribunal Constitucional e interpretación consti1995 tucional». En Lecturas Constitucionales Andinas. No. 4. Lima, Comisión Andina de Juristas.

Sánchez Agesta, Luis. Curso de Derecho Constitucional Comparado. 1980 Madrid, Universidad Complutence.

Sánchez Agesta, Luis y otros. Documentos constitucionales y textos politi1982 cos. Madrid, Editorial Nacional.

Schмiтt, Carl. Teoria de la Constitución. Madrid, Alianza Universidad 1992 Textos.

Serria, María Mercedes. Proceso Constitucional. En Revista Juridica 1991 Argentina La Ley. Tomo 1990-E. Argentina.

Serra, María Mercedes. Procesos y recursos constitucionales. Buenos Ai1992 res, Ediciones Depalma.

Silva Panez, Max. El fenómeno del poder politico y su enseñanza en la Fa1995 cultad de Derecho y Ciencias Politicas. Tesis presentada para obtener el título de abogado en la Facultad de Derecho y Ciencias Políticas de la Universidad de Lima y que fuera aprobada por unanimidad, con el calificativo de muy bien y recomendación de publicación, Lima.

Toruela, Juan. «La justicia constitucional en Estados Unidos y Costa

1993 Rica». En el colectivo La jurisdicción constitucional. Costa Rica, Editorial Juricentro.

Torres y Torres Lara, Carlos. La nueva Constitución del Perú 1993: 1993 antecedentes, fundamentos e historia documentada. Lima, Desarrollo y Paz.

Ugarte del Pino, Juan Vicente. Historia de las constituciones del Perú. 1978 Lima, Editorial Andina S.A. 
Universidad Externado de Colombia. La jurisdicción constitucional en 1984 Iberoamérica. Bogotá, UNEC.

Valencia Vega, Alipio. Manual de Derecho Constitucional. La Paz, Li1985 brería Editorial Juventud.

Valle-Riestra, Javier. El Tribunal de Garantias Constitucionales. El caso 1986 de los votos nulos y blancos. Lima, Editorial Labrusa S.A., 1986.

Vanossi, Jorge Reynaldo. El Estado de Derecho en el constitucionalismo 1982 social. Buenos Aires, Editorial Universitaria de Buenos Aires.

Vásquez Carrisosa, Alfredo. El Poder presidencial en Colombia. Bogotá, 1986 Ediciones Suramérica.

Vescovi, Enrique. Teoria General del Proceso. Bogotá, Temis. 1984

Vidal Cobián, Ana María. «Funciones del Tribunal de Garantías Cons1984 titucionales". En Revista del Foro. No. 2. Lima.

Zonatto, Daniel. Los estados de excepción y los derechos humanos en Amé1990 rica Latina. Caracas-San José, IIDH y Editorial Jurídica Venezolana. 